\title{
Progress and innovation of nanostructured sulfur cathodes and metal-free anodes for room-temperature $\mathrm{Na}-\mathrm{S}$ batteries
}

\author{
Marina Tabuyo-Martínez, Bernd Wicklein ${ }^{*}$ and Pilar Aranda
}

\author{
Review \\ Address: \\ Instituto de Ciencia de Materiales de Madrid (ICMM), Consejo \\ Superior de Investigaciones Científicas (CSIC), 28049 Madrid, Spain

\section{Email:} \\ Bernd Wicklein* - bernd@icmm.csic.es \\ * Corresponding author \\ Keywords: \\ composites; metal-free anode; Na-S; sodium nanostructures; \\ sodium-sulfur batteries; sulfur nanostructures
}

Beilstein J. Nanotechnol. 2021, 12, 995-1020.

https://doi.org/10.3762/bjnano.12.75

Received: 30 April 2021

Accepted: 19 August 2021

Published: 09 September 2021

Associate Editor: W.-J. Ong

(C) 2021 Tabuyo-Martínez et al.; licensee Beilstein-Institut.

License and terms: see end of document.

\begin{abstract}
Rechargeable batteries are a major element in the transition to renewable energie systems, but the current lithium-ion battery technology may face limitations in the future concerning the availability of raw materials and socio-economic insecurities. Sodium-sulfur $(\mathrm{Na}-\mathrm{S})$ batteries are a promising alternative energy storage device for small- to large-scale applications driven by more favorable environmental and economic perspectives. However, scientific and technological problems are still hindering a commercial breakthrough of these batteries. This review discusses strategies to remedy some of the current drawbacks such as the polysulfide shuttle effect, catastrophic volume expansion, Na dendrite growth, and slow reaction kinetics by nanostructuring both the sulfur cathode and the $\mathrm{Na}$ anode. Moreover, a survey of recent patents on room temperature (RT) Na-S batteries revealed that nanostructured sulfur and sodium electrodes are still in the minority, which suggests that much investigation and innovation is needed until RT Na-S batteries can be commercialized.
\end{abstract}

\section{Introduction}

The progress and innovation of cheaper, cleaner, safer, and more efficient electrical energy storage systems is essential for sustainable development $[1,2]$. Not only would it allow for a longer operation range of electronic devices such as mobile consumer electronics, electric vehicles, and stationary energy storage systems. It would also reduce fossil fuel reliance and greenhouse gas emissions if charged with "green electricity". Therefore, improving energy storage may lead to more sustain- able energy consumption [3]. In this context, rechargeable batteries play an important role owing to the fact that electrochemical energy storage is more efficient than physical energy storage [4].

Today, lithium-ion batteries (LiBs) are undoubtedly the most important mobile electrical energy storage devices. Nevertheless, they have some critical limitations such as high cost, low 
resource availability, as well as access and safety concerns $[1,5,6]$. Therefore, new promising batteries based on widely available anode and cathode materials are sought. Table 1 lists some abundant metals as anode materials with high capacity and reduction potential values that are explored in metal-ion batteries [7-9].

Besides sodium as alternative anode material, also sulfur as abundant cathode material has emerged due to the high theoretical capacities of both elements $\left(1166 \mathrm{mAh} \cdot \mathrm{g}^{-1}\right.$ and $1675 \mathrm{mAh} \cdot \mathrm{g}^{-1}$, respectively), which lead to devices with high energy density $[4,10]$. Additionally, sulfur cathodes exhibit other advantages such as low operating voltages $(1.81 \mathrm{~V}$ vs $\mathrm{Na} /$ $\left.\mathrm{Na}^{+}\right)$and improved safety and low toxicity compared with transition-metal compounds in lithium-ion batteries [11]. Consequently, sodium-sulfur $(\mathrm{Na}-\mathrm{S})$ batteries have attracted renewed attention over the last decade due to their low cost and comparable chemistry with $\mathrm{Li}-\mathrm{S}$ and $\mathrm{LiB}$ batteries, which would facilitate the large-scale production of $\mathrm{Na}-\mathrm{S}$ batteries [3,12]. In fact, research on $\mathrm{Na}$ batteries is not new, starting with high-temperature (HT) Na-S batteries in the 1960s and RT sodium-ion batteries (SiBs) in the 1980s [10]. However, an appropriate anode material based on sodium was not achieved and, therefore, only lithium-ion batteries are commercially available for room-temperature applications [10].

The first commercialized Na-S battery was a high-temperature sodium-sulfur battery, which has an operational temperature in the range of $270-350{ }^{\circ} \mathrm{C}$ [13]. It was launched to the market by NGK Insulator Co. in Japan in 2002. However, these devices had important security and corrosion issues since sodium and sulfur are both liquid under the working conditions. Therefore, the applicability of HT Na-S batteries is limited to stationary deployment, and the operation temperature needs to be reduced in order to improve market penetration of $\mathrm{Na}-\mathrm{S}$ batteries. As a result of scientific investigations and technological innovations, room-temperature sodium-sulfur (RT Na-S) batteries have been gaining importance since the mid-2000s $[3,10,14]$. A lot of effort is focused on the development of different cathode materials in order to produce commercial high-efficiency RT Na-S batteries (vide infra).

The electrochemical mechanism of RT Na-S batteries is based on the release of sodium cations from the anode leading to the transfer of two electrons that reduce sulfur on the cathode side (Figure 1A) [4]. The redox reactions of the battery are as follows (the discharge process corresponds to the reactions from left to right):

$$
\begin{array}{ll}
\text { Anode: } & 2 \mathrm{Na} \rightleftarrows 2 \mathrm{Na}^{+}+2 \mathrm{e}^{-}, \\
\text {Cathode: } & x \mathrm{~S}+2 \mathrm{e}^{-} \rightleftarrows \mathrm{S}_{x}^{2-}, \\
\text { Global reaction: } & 2 \mathrm{Na}+x \mathrm{~S} \rightleftarrows \mathrm{Na}_{2} \mathrm{~S}_{x} .
\end{array}
$$

Considering the full reduction of sulfur to $\mathrm{Na}_{2} \mathrm{~S}$, RT $\mathrm{Na}-\mathrm{S}$ batteries have a high theoretical energy density of $1276 \mathrm{Wh} \cdot \mathrm{kg}^{-1}$ [4]. However, the reduction of sulfur to sodium sulfide is not a one-step process as it proceeds in a series of intermediate reactions [15], that is, (1) the transformation of sulfur into long-chain polysulfides: $4 \mathrm{Na}+\mathrm{S}_{8} \rightleftharpoons 2 \mathrm{Na}_{2} \mathrm{~S}_{n}$ $(4<n \leq 8)$, (2) the transformation of long-chain into short-chain polysulfides: $2 \mathrm{Na}+\mathrm{Na}_{2} \mathrm{~S}_{4} \rightleftharpoons 2 \mathrm{Na}_{2} \mathrm{~S}_{m}(2 \leq m<4)$, and (3) the transformation of short-chain polysulfides into sodium sulfide: $2 \mathrm{Na}+\mathrm{Na}_{2} \mathrm{~S}_{2} \rightleftharpoons 2 \mathrm{Na}_{2} \mathrm{~S}$. The intermediate sodium polysulfides are formed during the charge-discharge process (Figure 1B) and have important effects on the battery function, including the so-called polysulfide shuttle effect (vide infra) [4].

Technical problems of RT Na-S batteries compromise their performance and prevent their commercialization. The main drawbacks of these electrochemical devices are (1) the polysulfide shuttle effect, (2) the insulating nature of both sulfur and sodium sulfide, and (3) the large volume expansion of the cathode during the discharge process (Figure 2) [16]. Other important challenges are $\mathrm{Na}$ dendrite formation, capacity fading, low elec-

\begin{tabular}{|c|c|c|c|c|}
\hline Metal & $\begin{array}{l}\text { Gravimetric capacity } \\
\left(\mathrm{mAh} \cdot \mathrm{g}^{-1}\right)\end{array}$ & $\begin{array}{l}\text { Volumetric capacity } \\
\left(\mathrm{mAh} \cdot \mathrm{cm}^{-3}\right)\end{array}$ & $\begin{array}{l}\text { Reduction potential } \\
\text { (V vs SHE) }\end{array}$ & $\begin{array}{l}\text { Abundance in Earth's crust } \\
\text { (ppm) }\end{array}$ \\
\hline $\mathrm{Li}$ & 3862 & 2062 & -3.04 & $20(0.002 \%)$ \\
\hline $\mathrm{Na}$ & 1165 & 1128 & -2.71 & $23,600(2.36 \%)$ \\
\hline $\mathrm{K}$ & 685 & 591 & -2.93 & $20,900(2.09 \%)$ \\
\hline $\mathrm{Mg}$ & 2205 & 3833 & -2.37 & $23,300(2.33 \%)$ \\
\hline $\mathrm{Ca}$ & 2073 & 1337 & -2.87 & $41,500(4.15 \%)$ \\
\hline $\mathrm{Al}$ & 2980 & 8046 & -1.66 & 82,300 (8.23\%) \\
\hline $\mathrm{Zn}$ & 820 & 5851 & -2.20 & $70(0.007 \%)$ \\
\hline
\end{tabular}
trochemical utilization of sulfur, large size and mass of sodium

Table 1: Metals used as anode material in metal-ion batteries including their theoretic capacities, reduction potential, and abundance [7-9]. 
A

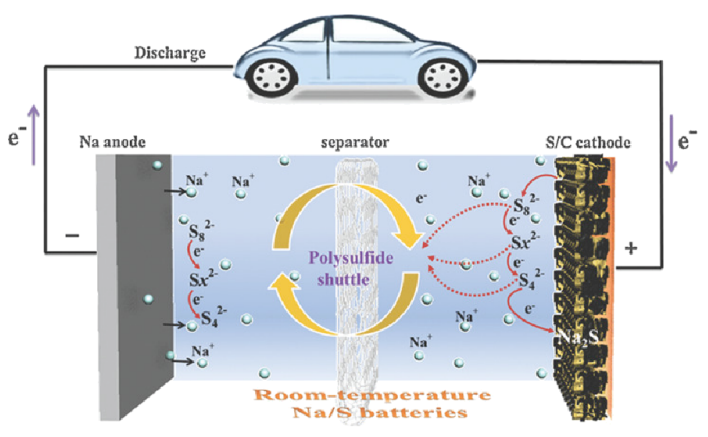

B

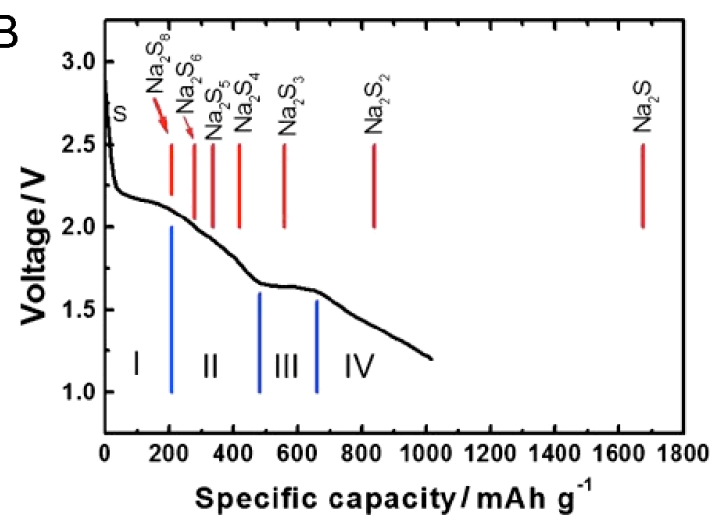

Figure 1: (A) Schematic representation of the electrochemical processes taking place in a RT Na-S battery. Figure $1 \mathrm{~A}$ was reproduced with permission from [16], Y.-X. Wang et al. "Room-Temperature Sodium-Sulfur Batteries: A Comprehensive Review on Research Progress and Cell Chemistry", Adv. Energy Mater., with permission from John Wiley and Sons. Copyright $@ 2017$ WILEY-VCH Verlag GmbH \& Co. KGaA, Weinheim. This content is not subject to CC BY 4.0. (B) Theoretical discharge capacities (red lines) versus a discharge profile (black) of a representative RT Na-S cell prepared with a continuous carbon fiber interlayer. Figure 1B was reproduced with permission from [17], X. Yu et al. "Capacity Enhancement and Discharge Mechanisms of Room-Temperature Sodium-Sulfur Batteries", ChemElectroChem, with permission from John Wiley and Sons. Copyright @ 2014 WILEY-VCH Verlag GmbH \& Co. KGaA, Weinheim. This content is not subject to CC BY 4.0.

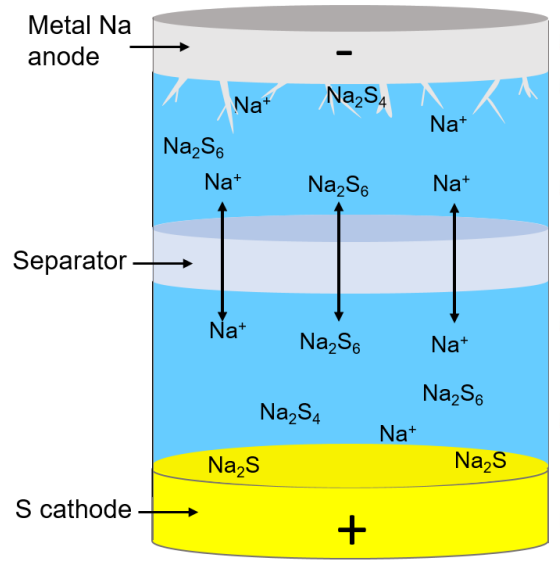

$\triangle$ Na metal safety issues

$\triangle \mathrm{Na}$ dendrite growth

$\triangle$ Shuttle effect

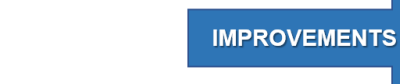

$\triangle$ Slow reaction kinetics

$\triangle$ Volume expansion

$\triangle \mathrm{S}$ and $\mathrm{Na}_{2} \mathrm{~S}$ low conductivity
- Na nanostructures

- Na alloys / intermetallics

- Hard carbon

- Hard carbon

a metal-

free anode

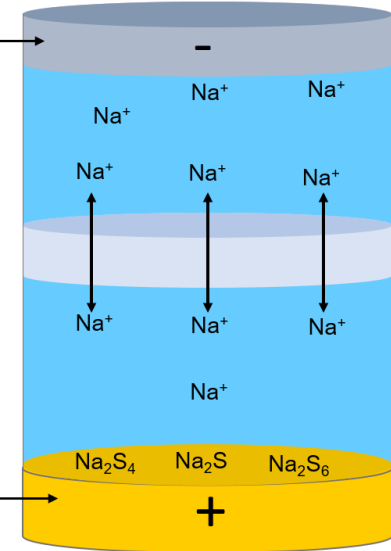

S-C nanocomposites

- S nanoparticles

- Transition/noble metal NPs

Figure 2: Some of the principal challenges of RT Na-S batteries and potential improvements by nanostructuring both the sulfur cathode and the Na anode as discussed below.

ions, and poor understanding of the formation of discharge products [18]. In addition, replacing metal $\mathrm{Na}$ anodes with safer materials is another critical barrier to overcome $[10,19,20]$. It is essential to solve these issues to achieve high efficiency devices that can be launched onto the market.

In this review, we focus on the first three drawbacks and potential strategies, including advanced cathode materials, to overcome them. The polysulfide shuttle effect is a phenomenon caused by the migration of long-chain sodium polysulfides $\left(\mathrm{Na}_{2} \mathrm{~S}_{n}\right)$ to the anode, facilitated by their high solubility in carbonate- and ether-based electrolytes [21]. At the anode, $\mathrm{Na}_{2} \mathrm{~S}_{n}$ is further reduced to insoluble short-chain sodium polysulfides, which precipitate and passivate the electrode. These reactions are not fully reversible and lead to capacity loss of the battery $[3,22]$ together with a low utilization of active material, low Coulombic efficiency, and poor cycle life [4,11]. Effective remedies for suppressing the shuttle effect are (1) capturing the 
soluble $\mathrm{Na}_{2} \mathrm{~S}_{n}$ within the cathode and (2) incorporating ionselective membranes and blocking separator interlayers [14]

The insulating nature of sulfur and sodium sulfide is also problematic due to the importance of a highly conductive cathode to obtain a good performance of the RT Na-S battery. Therefore, it is necessary to design a cathode material that improves the conductivity of the system [4,11]. Common approaches are based on the incorporation of conductive carbon nanomaterials [23].

The volume expansion of sulfur during the discharge process is caused by the formation of the discharge product $\mathrm{Na}_{2} \mathrm{~S}$. This expansion is rather large (up to $170 \%$ ) and may damage the cathode and lead to capacity loss [4]. Nanoscaling the cathode compounds and the concomitant introduction of porosity is a widely investigated strategy to mitigate the emerging mechanical tension and to prevent electrode failure $[18,24]$.

Unlike sodium-ion batteries, the anode of most $\mathrm{RT} \mathrm{Na}-\mathrm{S}$ batteries simply consists of a $\mathrm{Na}$ metal foil. This has severe security and technological implications as metallic $\mathrm{Na}$ is highly reactive, prone to dendrite growth and subsequent mechanical failure, and reduced cycle performance [10]. These inconveniences are detrimental to the expansion of these batteries into wider consumer markets, for which hard carbon, $\mathrm{Si}, \mathrm{Sn}$ and $\mathrm{Sb}$ alloys, as well as phosphorous compounds are currently investigated [25-27].

This review focuses on the most recent designs of cathode materials for RT Na-S batteries, which attempt to overcome the drawbacks of sulfur-based cathodes. The strategies to solve the polysulfide shuttle effect, conductivity drop, and structural damage caused by sulfur volume expansion are discussed. Moreover, concepts for $\mathrm{Na}$ metal-free anodes in $\mathrm{Na}-\mathrm{S}$ batteries are reviewed and analyzed. Other strategies including electrolyte engineering, cell design, interlayers, or solid electrolyte interphases can be found elsewhere in excellent reviews $[10,14,28]$. Here, additionally, some patents are reviewed to examine the approaches that are followed to commercialize $\mathrm{Na}-\mathrm{S}$ batteries. Finally, an outlook is provided on how far this technology has currently developed and where future research could be directed at.

\section{Review \\ Conventional sulfur-carbon cathode materials}

Sulfur-carbon composites are the most widely studied cathode materials because carbon increases the cathode conductivity and also improves the reactivity of sulfur [4]. Since carbon struc- tures are highly diverse, a huge variety of cathode materials have been designed and tested in RT Na-S batteries. Here, the sulfur-carbon composites are classified in two main categories: (1) sulfur-porous carbon composites and (2) covalently bound sulfur-carbon composites.

\section{Sulfur-porous carbon composites}

Hollow and porous carbon structures may not only increase cathode conductivity, but can also allow for physical confinement of long-chain sodium polysulfides and reduce the structural damage caused by sulfur volume expansion [4,11]. This makes sulfur-porous carbon composites remarkably promising cathode materials for RT Na-S batteries. Among the different studied materials are, for instance, microporous (Figure 3) and ultramicroporous carbon materials, which have shown a considerable ability to confine sulfur and sodium polysulfides [29,30]. This confinement significantly improves the cycling stability since the shuttle effect is minimized. For instance, a capacity of $300 \mathrm{mAh} \cdot \mathrm{g}^{-1}$ after 1500 cycles at $1 \mathrm{C}$ and a Coulombic efficiency of $98 \%$ can be achieved (Figure 3A) [29].

Furthermore, hierarchical porous carbon structures have also shown promising performance as sulfur host material [24,31]. As an example, Zhang et al. [24] designed a sulfur host based on porous double-shell microspheres, which consist of hollow carbon nanobeads inside a microsized carbon shell. In this structure, sulfur is infused in the nanobeads inside the microspheres and neither sulfur nor sodium polysulfide species are directly exposed to the electrolyte. Additionally, the hollow structure provides space to accommodate the volume expansion of sulfur during the discharge processes. This cathode composite limits the shuttle effect, increases utilization and activity of sulfur, and prevents cathode damage due to the volume change of sulfur. Therefore, an improvement in charge capacity (300 vs $50 \mathrm{mAh} \cdot \mathrm{g}^{-1}$ ) and cycling stability is achieved when comparing the double- with single-shell carbon microspheres as shown in Figure 3B.

In addition, modified porous carbon structures with nitrogen or oxygen doping have proven to enhance the immobilization of sodium polysulfides leading to an advancement in battery performance [31,32]. Adsorption and trapping of polysulfides are achieved through strong interactions between the sodium atoms in sodium polysulfides and the nitrogen and oxygen atoms. The shuttle effect is therefore diminished, which results in an improvement in cycling stability. In this way, Qiang et al. [31] reported a decay in discharge capacity of only $3 \%$ after 8000 cycles at a high current density of $4.6 \mathrm{~A} \cdot \mathrm{g}^{-1}$. This improvement has also been clearly shown in the electrochemical performance of the RT Na-S battery reported by Xia et al. [32] who used nitrogen-doped hollow carbon nanobubbles sup- 

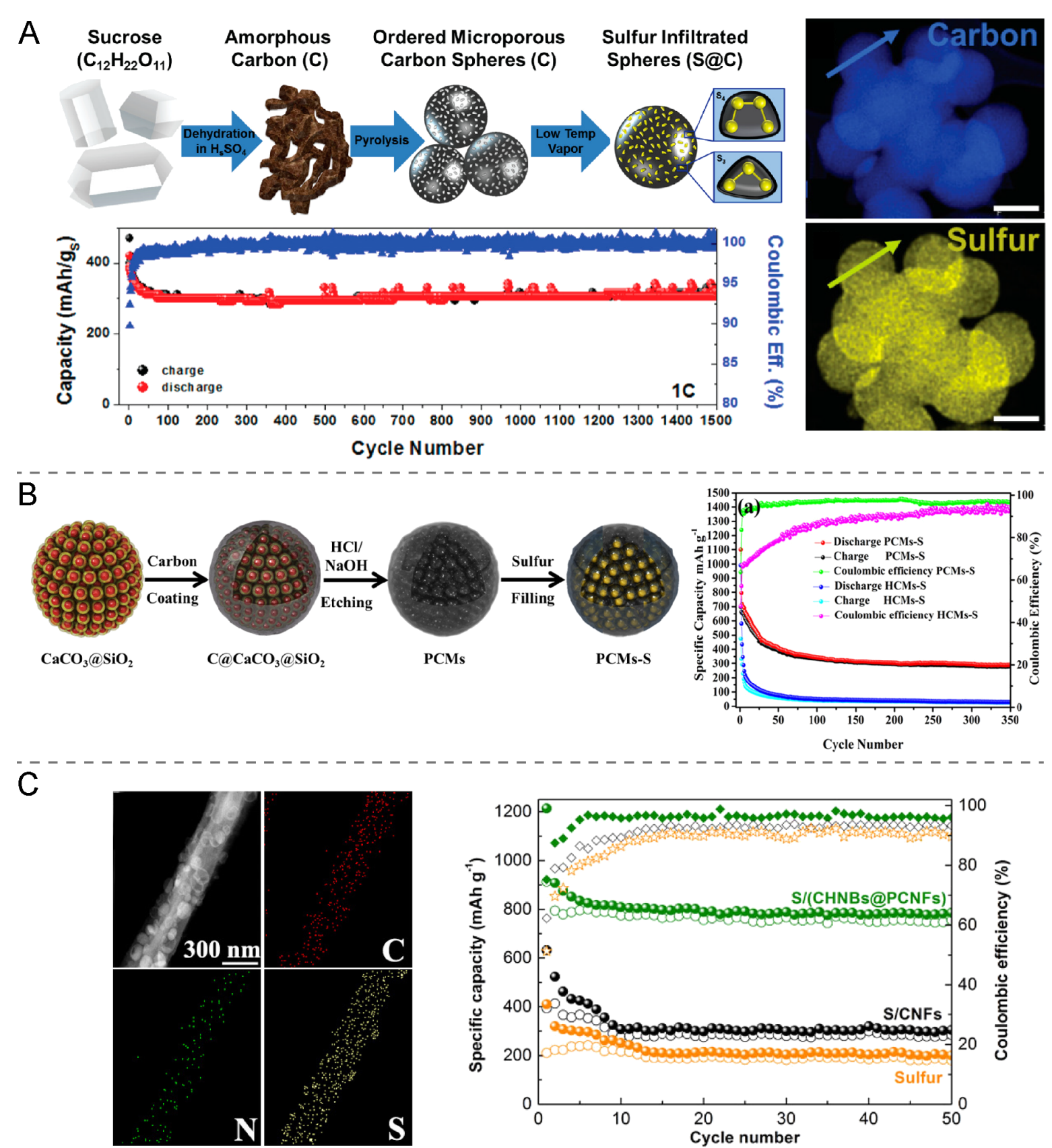

Figure 3: (A) Schematic illustration of the processing steps of using sucrose to produce microporous, sulfur-infiltrated carbon spheres (S@C). The STEM EDS maps of S@C show carbon (blue) and sulfur (yellow). The capacity and Coulombic efficiency plotted over 1500 cycles at 1C. Figure 3A was reprinted with permission from [29]. Copyright 2017, The American Chemical Society. This content is not subject to CC BY 4.0. (B) Schematic illustration of the fabrication process of porous carbon microspheres filled with sulfur (PCMs-S) and the respective cycling properties of double- and single-shell carbon microspheres (PCMs-S vs HCMs-S) at $100 \mathrm{~mA} \cdot \mathrm{g}^{-1}$. Figure 3B was reprinted with permission from [24]. Copyright 2018, The American Chemical Society. This content is not subject to CC BY 4.0. (C) Scanning STEM image and the corresponding elemental mapping of S containing carbon hollow nanobubbles on porous carbon nanofibers and the cycling performance at a current density of $0.1 \mathrm{C}$. Figure $3 \mathrm{C}$ was reprinted from [32], Energy Storage Materials, vol. 14, by G. Xia, L. Zhang, X. Chen, Y. Huang, D. Sun, F. Fang, Z. Guo, X. Yu, "Carbon hollow nanobubbles on porous carbon nanofibers: An ideal host for high-performance sodium-sulfur batteries and hydrogen storage", pages no. 314-323. Copyright (2018), with permission from Elsevier. This content is not subject to CC BY 4.0.

ported on porous carbon nanofibers as sulfur hosts. The nitrogen content of this carbonaceous structure is shown by a mapping image in Figure 3C. When studying the electrochemi- cal properties of this material, improved results are obtained with a cycle life of up to 400 cycles and a small capacity decay rate of $0.044 \%$ per cycle. 
Moreover, Chen et al. [33] reported the potential use of metalorganic frameworks as cathode skeleton. Herein, a sulfur host based on a nanoporous nitrogen-doped carbon matrix was obtained through carbonization of a zeolitic imidazolate framework (ZIF-8). The cathode exhibits good performance with a reversible specific capacity of $500 \mathrm{mAh} \cdot \mathrm{g}^{-1}$ after 250 cycles at $0.2 \mathrm{C}$. The excellent electrochemical behavior is based on the efficient polysulfide entrapment as result of the nanoporosity of the carbon matrix and the high nitrogen-doping content (ca. 18 atom \%).

Among all sulfur-carbon composite cathodes, flexible carbonbased skeletons are one of the most promising cathode materials given their ability to accommodate the fast volume changes of sulfur during the discharge process. Ma et al. [34] reported a conductive and flexible graphene aerogel cathode that effectively tolerated the volume changes under stabilization of the structure and led to an outstanding performance, showing an initial discharge capacity of $572.8 \mathrm{mAh} \cdot \mathrm{g}^{-1}$ at $5 \mathrm{C}$ and an extremely low average capacity fading.

\section{Covalently bound sulfur-carbon cathodes}

Cathodes with sulfur covalently bound to carbon are promising materials because the strong sulfur-carbon bond prevents polysulfides from dissolving and migrating, thus mitigating the shuttle effect. Therefore, an enhancement of the battery cycling stability can be achieved. Many different materials might be used as cathode skeleton. As an example, Huo et al. [35] reported the use of a two-dimensional layered material $\mathrm{Ti}_{3} \mathrm{C}_{2} \mathrm{~T}_{x}$ (where $\mathrm{T}_{x}$ are surface functional groups such as $\mathrm{F}_{2}$ and $(\mathrm{OH})_{2}$ ) into which sulfur was inserted by a simple melt/sublimation process forming $\mathrm{C}-\mathrm{S}$ bonds within the MXene. This cathode shows reasonable cycle stability $\left(150 \mathrm{mAh} \cdot \mathrm{g}^{-1}\right.$ after 300 cycles at $100 \mathrm{~mA} \cdot \mathrm{g}^{-1}$ ), however the sulfur loading process needs to be optimized to obtain a RT Na-S battery with higher capacity values. Yan et al. [36] reported a covalent sulfur-carbon composite prepared from $\mathrm{CS}_{2}$ (Figure 4A) that delivers high reversible capacities of $889 \mathrm{mAh} \cdot \mathrm{g}^{-1}$ after 600 cycles at $0.8 \mathrm{C}$ and of $811 \mathrm{mAh} \cdot \mathrm{g}^{-1}$ after 950 cycles at $1.6 \mathrm{C}$. Additionally, Wu et al. [37] reported a cathode material based on a covalent sulfur-carbon complex with a high concentration of covalently bonded sulfur (40.1\%), which displays a specific capacity of $696 \mathrm{mAh} \cdot \mathrm{g}^{-1}$ at $2.5 \mathrm{~A} \cdot \mathrm{g}^{-1}$. Unlike most of the reported cathodes, where sulfur is infused in its elemental form $\left(S_{8}\right)$, in this design the sulfur source are benzenedisulfonic acid (BDSA, $\left.-\mathrm{SO}_{3} \mathrm{H}\right)$ and sulfate $\left(\mathrm{SO}_{4}{ }^{2-}\right)$, which are shown in Figure 4B. Moreover, the carbon structure in the cathode has mesopores and, therefore, can confine a certain amount of sulfur and polysulfides. In addition to the confinement, the generated polysulfides can also be anchored by the partially oxidated sulfur-carbon units (R-SO) and form insoluble surface-bound intermedi- ates. Consequently, the shuttle effect is minimized resulting in excellent cycle stability for 1000 cycles with $0.035 \%$ capacity decay per cycle.

The research based on covalently bonded sulfur-carbon cathodes has been mostly focused on electrodes with a polyacrylonitrile (PAN) skeleton [38-41]. For instance, Hwang et al. [39] reported a cathode material based on one-dimensional sulfurized PAN nanofibers, and Kim et al. [40] reported the design of a flexible cathode that consists of a sulfurized PAN nanofiber web. The sulfurized PAN web was prepared by pyrolysis of PAN nanofibers and elemental sulfur at $450{ }^{\circ} \mathrm{C}$ for $6 \mathrm{~h}$ in an inert gas atmosphere. Both electrodes exhibit an excellent cycling performance because the shuttle effect and the low conductivity of elemental sulfur are avoided [39,40]. However, its applicability is hindered due to the low capacity values achieved. The former cathode is reported to display a capacity of $153 \mathrm{mAh} \cdot \mathrm{g}^{-1}$ after 500 cycles at 1C [39], while the latter has $257 \mathrm{mAh} \cdot \mathrm{g}^{-1}$ after 200 cycles at 1C [40]. This problem is a consequence of the low sulfur content of the polymer, which is usually less than $50 \mathrm{wt} \%$ and the limited redox reactivity of sulfur $[38,41]$. In order to overcome the consequences of the limited reactivity, a small amount of selenium can be added to the cathode and uniformly distributed through selenium-sulfur bonds. A significant improvement in redox reaction kinetics is achieved since selenium has a higher conductivity than sulfur and acts as an accelerator [38]. Therefore, the resulting cathode exhibits an improved cycling performance as shown in Figure 4C. A high specific capacity of $770 \mathrm{mAh} \cdot \mathrm{g}^{-1}$ after 200 cycles at $0.4 \mathrm{~A} \cdot \mathrm{g}^{-1}$ with a small capacity decay per cycle of $0.045 \%$ was obtained [38].

Additionally, Li et al. [41] reported a pyrolyzed $\mathrm{PAN} / \mathrm{SeS}_{2}$ composite that results in a cathode with excellent reaction kinetics, high capacity, and extremely stable cycle life. The multichannel framework of the composite provides more surface area of PAN to react with $\mathrm{SeS}_{2}$, leading to an enhancement of the sulfur load on the cathode to about $63 \mathrm{wt} \%$ of $\mathrm{SeS}_{2}$. As a result, the cathode exhibits a reversible capacity of $800 \mathrm{mAh} \cdot \mathrm{g}^{-1}$ after 400 cycles at $1 \mathrm{~A} \cdot \mathrm{g}^{-1}$.

\section{Sodium polysulfide composites as cathodes}

Long-chain sodium polysulfide composites emerged as an alternative to cathode composites using elemental sulfur as active material. This is because both $\mathrm{Na}_{2} \mathrm{~S}_{8}$ and the reduction products, $\mathrm{Na}_{2} \mathrm{~S}_{n}(4<n<8)$, show higher electrical conductivity than elemental sulfur and sodium sulfide $\mathrm{Na}_{2} \mathrm{~S}$ and faster reaction kinetics with $\mathrm{Na}^{+}$[42]. Therefore, by employing the $\mathrm{S} / \mathrm{Na}_{2} \mathrm{~S}_{n}$ redox couple as cathode, the electrode conductivity is enhanced, which improves the discharge efficiency and the sulfur utilization rate. In this battery design, the cathode reactions do not 

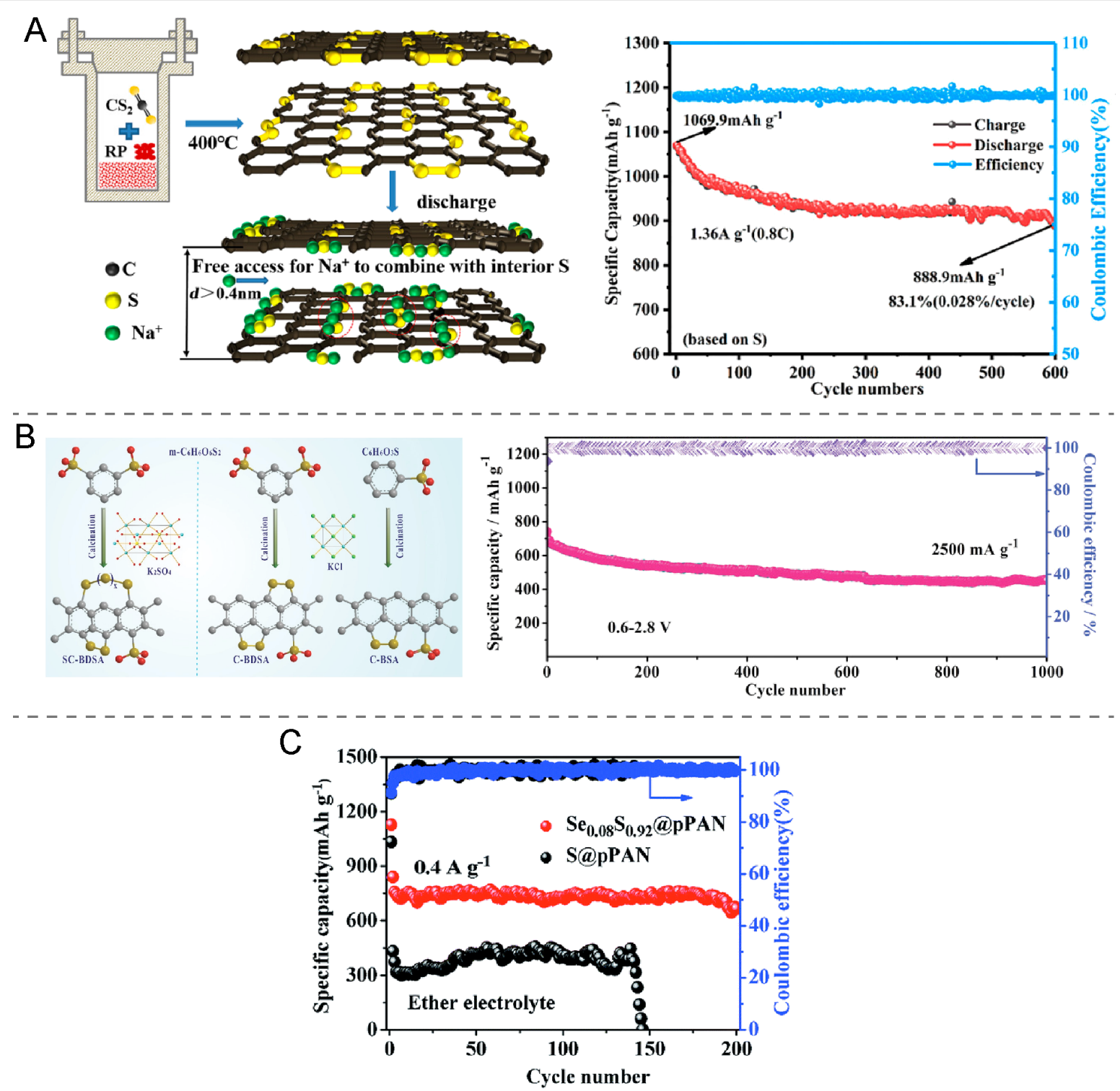

Figure 4: (A) Schematic illustration of preparation and structure of the covalent sulfur-carbon composite synthesized with $\mathrm{CS}_{2}$ and red phosphorus and the corresponding long cycle performance at $0.8 \mathrm{C}$. Figure $4 \mathrm{~A}$ was reprinted with permission from [36]. Copyright 2020, The American Chemical Society. This content is not subject to CC BY 4.0. (B) Schematic representation of the synthesis processes of C-BSA, C-BDSA, and SC-BDSA and the cyclic performance and Coulombic efficiency of the activated SC-BDSA electrode for $\mathrm{Na}-\mathrm{S}$ battery system at $2500 \mathrm{~mA} \cdot \mathrm{g}^{-1}$ for $1000 \mathrm{cycles}$. Figure 4B was reprinted with permission from [37], T. Wu et al. "Controllable Chain-Length for Covalent Sulfur-Carbon Materials Enabling Stable and High-Capacity Sodium Storage", Adv. Energy Mater., with permission from John Wiley and Sons Copyright @ 2019 WILEY-VCH Verlag GmbH \& Co. KGaA, Weinheim. This content is not subject to CC BY 4.0. (C) Cycling performance of $\mathrm{Se}_{0.08} \mathrm{~S}_{0.92} @ p P A N$ and S@pPAN in an ether electrolyte. Figure 4C was republished with permission of The Royal Society of Chemistry, from [38] ("Effect of eutectic accelerator in selenium-doped sulfurized polyacrylonitrile for high performance room temperature sodium-sulfur batteries" by L. Wang et. al., J. Mater. Chem. A, vol. 7, @ 2019); permission conveyed through Copyright Clearance Center, Inc. This content is not subject to CC BY 4.0".

proceed to sodium sulfide by properly adjusting the discharge cut-off voltage, avoiding low conductivity and irreversibility problems. However, a significant disadvantage of these composites is the fact that sodium polysulfides are incorporated as a liquid phase (so-called catholyte) and thus, it is necessary to confine them at the cathode. Otherwise, they would migrate to the anode and compromise the battery performance via the shuttle effect. Figure 5 shows an illustration of the resulting RT
$\mathrm{Na}-\mathrm{S}$ battery and the cycle performance. Another drawback is the lower theoretical cell capacity by not discharging until $\mathrm{Na}_{2} \mathrm{~S}$ is formed.

One approach to physically confine the catholyte is using membranes. Cengiz et al. [43] reported a RT Na-S battery with a $\mathrm{Na}_{2} \mathrm{~S}_{5}$ catholyte confined by a $\mathrm{Al}_{2} \mathrm{O}_{3}-\mathrm{Nafion}$ membrane. Using this barrier, the capacity retention could be improved to 
A

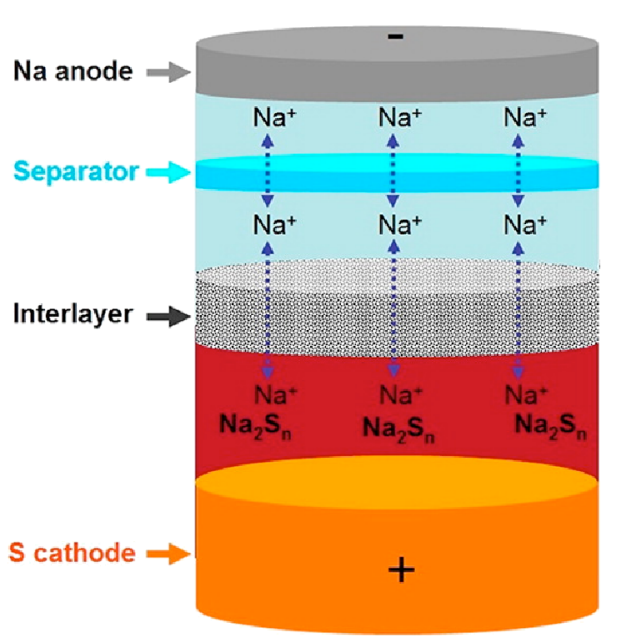

B

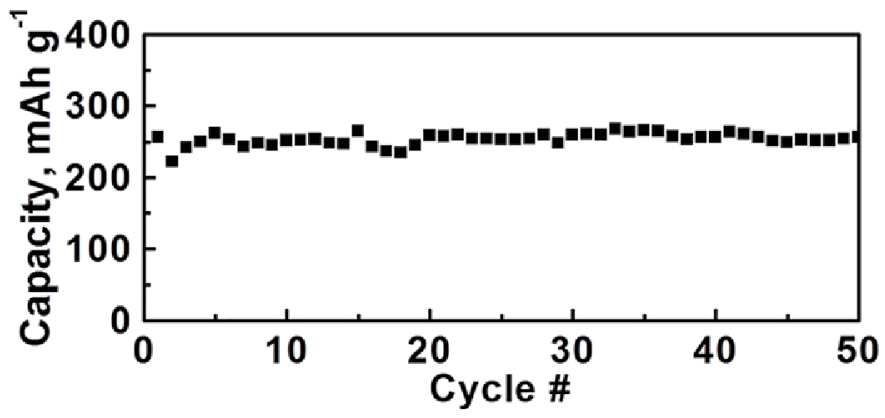

C

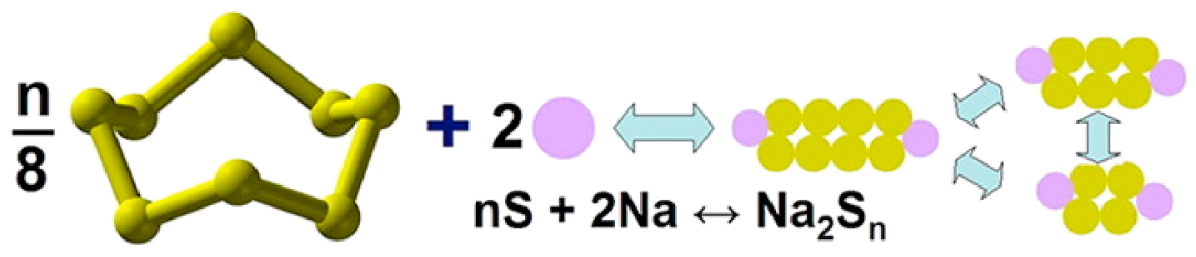

Figure 5: (A) Schematic representation of a RT Na-S battery with a liquid-phase catholyte containing polysulfides and an interlayer separating the anode from the cathode. (B) Discharge capacity of the sulfur/long-chain sodium polysulfide battery over 50 cycles. (C) Illustration of the reaction mechanism of $\mathrm{S}_{8}$ and $\mathrm{Na}$ to long-chain sodium polysulfide. Figure $4 \mathrm{~A}-\mathrm{C}$ was reprinted with permission from [42]. Copyright 2014, The American Chemical Society. This content is not subject to CC BY 4.0 .

$250 \mathrm{mAh} \cdot \mathrm{g}^{-1}$ after 100 cycles. In spite of the improvement, the capacity value is still low because of the low $\mathrm{Na}^{+}$diffusivity through the membrane and the insulating nature of $\mathrm{Al}_{2} \mathrm{O}_{3}$. Another approach to stable catholytes is combining the active material with free-standing, cloth-type carbonaceous materials. For instance, Yu et al. [22] reported the development of a cathode based on a sodium polysulfide catholyte soaked into a multiwall carbon nanotube (MWCNT) fabric. The resulting fabric $/ \mathrm{Na}_{2} \mathrm{~S}_{6}$ cathode exhibited higher capacity retention during cycling and higher active material utilization when compared with traditional sulfur-carbon composites. Additionally, using sodium polysulfides facilitates the dispersion and homogeneous distribution of sulfur into the nanostructured MWCNT matrix, which acts as a high-surface current collector. As a result, the sodium polysulfide/MWCNT fabric cathode delivers a discharge capacity of $400 \mathrm{mAh} \cdot \mathrm{g}^{-1}$ after 30 cycles.

\section{Transition metal nanoparticles as} polysulfide sequestrants and electrocatalysts As discussed above, hollow and porous carbonaceous structures, and in particular nitrogen or oxygen-doped carbonbased materials, are able to physically confine sodium polysul- fides, minimizing the shuttle effect. However, the interaction between the carbon structure and sodium polysulfides is generally weak since the former is a nonpolar material while the latter is a polar compound [12]. Therefore, the shuttle effect often cannot be avoided. In order to solve this limitation, transition metal nanoparticles (NPs) or compounds are incorporated in the cathode. The metallic species is bonded to the carbon skeleton creating a dipole, which leads to dipole-dipole interactions with the polysulfides. Thus, the sulfur host has stronger affinity to polysulfides, which get highly immobilized in the cathode.

Thus, Zheng et al. [44] reported on a cathode in which the shuttle effect is completely prevented. The sulfur host is based on copper nanoparticles deposited on high surface area mesoporous carbon (HSMC). The resulting electrode exhibited a Coulombic efficiency of $100 \%$ and a capacity of $610 \mathrm{mAh} \cdot \mathrm{g}^{-1}$ after 110 cycles at $0.03 \mathrm{C}$. This improved cycling stability was attributed to the conductivity enhancement imparted by copper, the sulfur immobilization due to strong copper-polysulfide interactions, and the free space for volume expansion that is provided by the HSMC matrix. 
In addition to sequestering polysulfides, transition metals may also act as electrocatalysts in the reduction reaction of longchain sodium polysulfides into short-chain sodium polysulfides or sodium sulfide. Consequently, the electrocatalysts accelerate the reaction kinetics, improving the electrochemical performance of $\mathrm{Na}-\mathrm{S}$ batteries. Different compounds were shown to have this property such as cobalt nanoparticles $[34,45,46]$, iron nanoclusters [47] and iron disulfide [48], gold nanodots [49], nickel sulfide nanocrystals [50], molybdenum trioxide [21], manganese dioxide [51], and vanadium carbide nanoparticles [12].

For instance, the electrocatalytic performance of cobalt nanoparticles (CoNPs) was reported by Zhang et al. [45] who studied a cathode comprising hollow carbon nanospheres. The cathode displayed a capacity of $271 \mathrm{mAh} \cdot \mathrm{g}^{-1}$ after 600 cycles at $0.1 \mathrm{~A} \cdot \mathrm{g}^{-1}$ before incorporating CoNPs and a value of $508 \mathrm{mAh} \cdot \mathrm{g}^{-1}$ after the addition (Figure 6A), suggesting the electrocatalytic role of CoNPs. Likewise, Du et al. [46] described a cathode with a skeleton based on nitrogen-doped porous carbon nanofibers and CoNPs that exhibited a capacity of $906 \mathrm{mAh} \cdot \mathrm{g}^{-1}$ at $0.1 \mathrm{C}$ and a long cycling life. Another carbon-Co structure was reported by Ma et al. [34] who developed a cathode made of a flexible graphene aerogel matrix that shows an extremely low capacity fading of $0.01 \%$ per cycle from 200 to 1000 cycles (Figure 6B). This performance was attributed to the enhanced reaction kinetics caused by the incorporated CoNPs and the accommodation of volume changes enabled by the flexible aerogel.

Also, transition metal nanoclusters that are smaller than nanoparticles were shown to enhance sulfur reactivity and avoid the shuttle effect. Zhang et al. [47] studied iron, copper, and nickel nanoclusters (ca $1.2 \mathrm{~nm}$ ) loaded onto hollow carbon nanospheres. On the one hand, the chemical coupling between nanocluster and sulfur assists in sulfur immobilization and enhances conductivity and reactivity. On the other hand, the electrocatalytic performance of the nanoclusters reduces long-chain polysulfides to short-chain polysulfides avoiding the shuttle effect. Among all of them, the iron nanoclusters displayed the most outstanding reversible capacity of initially $1023 \mathrm{mAh} \cdot \mathrm{g}^{-1}$ and $394 \mathrm{mAh} \cdot \mathrm{g}^{-1}$ after 1000 cycles at $0.1 \mathrm{~A} \cdot \mathrm{g}^{-1}$.

Yan et al. [48] also reported a promising cathode with iron in the form of iron disulfide nanoparticles as shown in Figure 6C. In order to explain the electrocatalytic behavior of $\mathrm{FeS}_{2}$, a twostep mechanism is proposed. Firstly, polysulfides are adsorbed on the surface of $\mathrm{FeS}_{2}$ NPs by strong chemical bonds and undergo a sodiation process to form $\mathrm{Na}_{2} \mathrm{~S}_{2}$. Then, the $\mathrm{Na}_{2} \mathrm{~S}_{2}$ intermediate is converted to $\mathrm{Na}_{2} \mathrm{~S}$. Another remarkable electrocatalyst are gold nanodots, as reported by Wang et al. [49]. The in situ synchrotron XRD results show that gold can effectively catalyze the transformation of $\mathrm{Na}_{2} \mathrm{~S}_{4}$ into $\mathrm{Na}_{2} \mathrm{~S}$ in the discharge process and of $\mathrm{Na}_{2} \mathrm{~S}_{4}$ into elemental sulfur in the charging process. Therefore, a complete conversion of polysulfides is achieved in both charge and discharge processes leading to an extraordinary high cycling stability $\left(430 \mathrm{mAh} \cdot \mathrm{g}^{-1}\right.$ after 1000 cycles at $2 \mathrm{~A} \cdot \mathrm{g}^{-1}$ and $369 \mathrm{mAh} \cdot \mathrm{g}^{-1}$ after 2000 cycles at $\left.10 \mathrm{~A} \cdot \mathrm{g}^{-1}\right)$ [49].

Metallic and metal oxide compounds have also attracted much interest due to their electronic conductivity and their high polarity, which leads to strong chemical interaction with polysulfides. For instance, Yan et al. [50] reported an electrode with an excellent performance that is based on nickel disulfide nanocrystals implanted in nitrogen-doped porous carbon nanotubes. It exhibits high reversible capacity of $650 \mathrm{mAh} \cdot \mathrm{g}^{-1}$ after 200 cycles at $0.1 \mathrm{~A} \cdot \mathrm{g}^{-1}$ and excellent cycling stability for 3500 cycles. Additionally, Kumar et al. [51] described a cathode, based on manganese dioxide in a carbon cloth as sulfur host and $\mathrm{Na}_{2} \mathrm{~S}_{6}$ catholyte as active material, that showed a reversible capacity of $610 \mathrm{mAh} \cdot \mathrm{g}^{-1}$ after 500 cycles at $0.2 \mathrm{~A} \cdot \mathrm{g}^{-1}$.

Likewise, a cathode where sulfur is used as the core layer and $\mathrm{MoO}_{3}$ is used as the catalytic shell layer was designed by Vijaya Kumar Saroja and co-workers [21]. Molybdenum trioxide prevents polysulfides from migrating due to its electrocatalytic and chemical sequestrant character. Therefore, a cycling stability of 2000 cycles was achieved. In the same way, a cathode with high capacity retention of $96.2 \%$ after 2000 cycles was presented by Tang and co-workers [12]. The electrode described is a three-dimensional self-supported structure with vanadium carbide nanoparticles embedded in carbon nanofibers.

Since these compounds are promising regarding efficient batteries, increased understanding of the mechanism of the electrocatalytic processes is essential to further develop cathode materials containing metallic species. As noted above, Tang et al. [12] reported that vanadium carbide nanoparticles capture longchain polysulfides and convert them into short-chain polysulfides through the catalytic mechanism schematically shown in Figure 6D. First, the vanadium carbide-carbon nanofibers (VC-CNFs) composite acts as electrocatalyst for oxidizing polysulfides to thiosulfate. Second, the thiosulfate serves as mediator to immobilize long-chain sodium polysulfides and transforming them to short-chain sodium polysulfides or sodium disulfide. Then, polysulfides are converted to polythionate $\left[\mathrm{O}_{3} \mathrm{~S}_{2}-(\mathrm{S})_{x-2}-\mathrm{S}_{2} \mathrm{O}_{3}\right]$ complexes bound to the electrode surface, which inhibits the shuttle effect [12]. A similar electrochemical mechanism has been reported by Kumar et al. [51] based on XPS analyses. The results show that the interaction between 


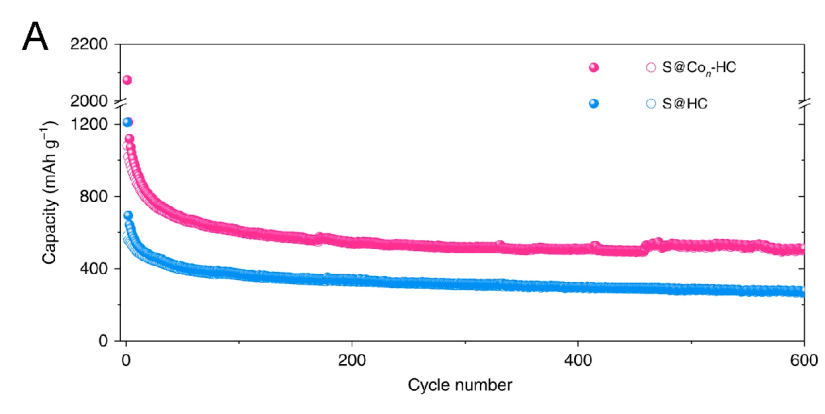

C
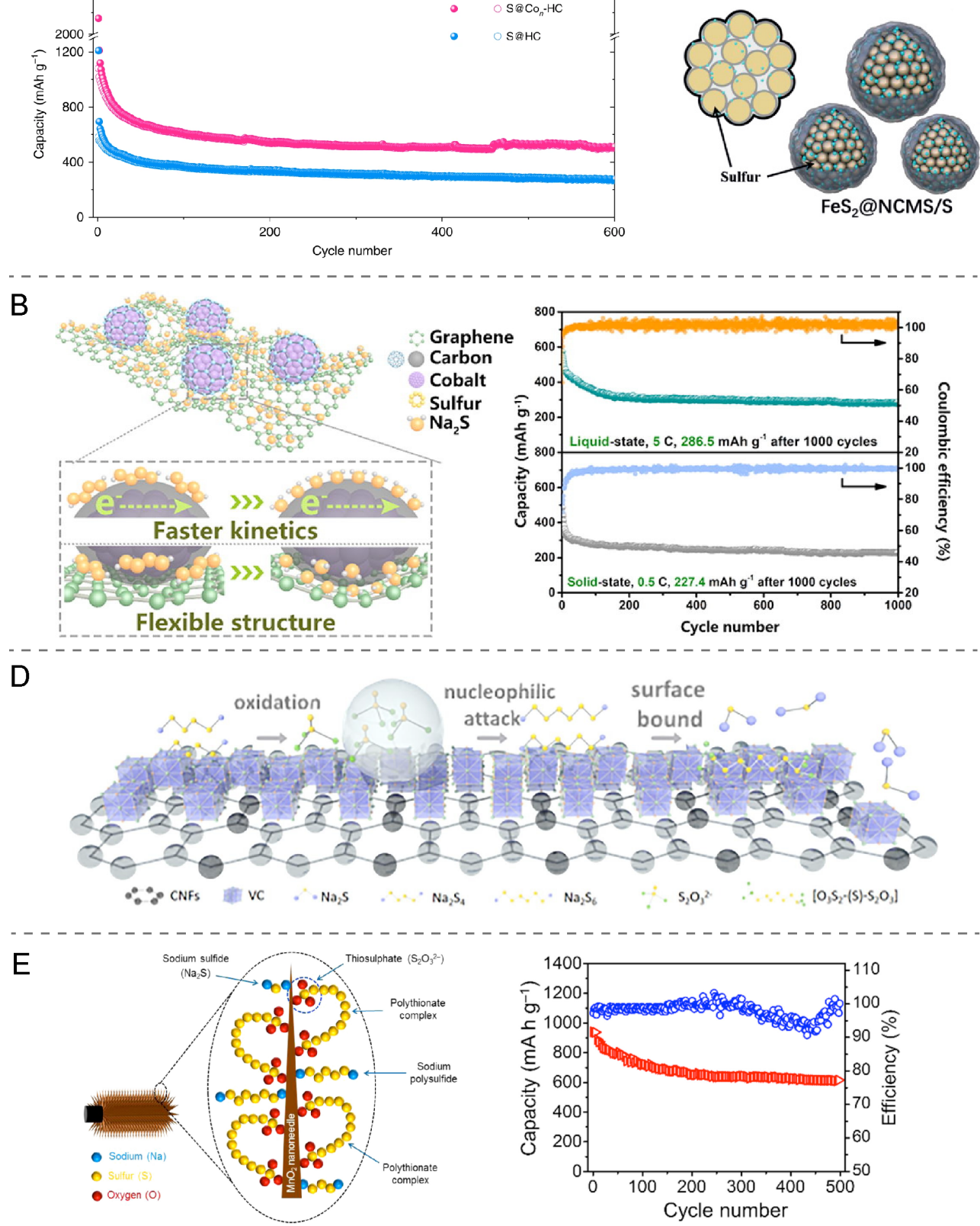

Figure 6: (A) Cycling performance of a sulfur-hollow carbon nanospheres cathode composite with and without cobalt nanoparticles. Figure 6A was reproduced from [45] (@ 2018 B. Zhang et al., published by Springer Nature, distributed under the terms of the Creative Commons Attribution 4.0 International License, https://creativecommons.org/licenses/by/4.0). (B) Schematic illustration of the S@Co/C/rGO composite electrode and its cycling performance in solid- and liquid-state RT/Na-S batteries. Figure 6B was reprinted from [34], Chemical Engineering Journal, vol. 388, by Q. Ma, G. Du, B. Guo, W. Tang, Y. Li, M. Xu, C. Li, "Carbon-wrapped cobalt nanoparticles on graphene aerogel for solid-state room-temperature sodium-sulfur batteries", article no. 124210. Copyright (2020), with permission from Elsevier. This content is not subject to CC BY 4.0. (C) Schematic illustration of the hierarchical FeS ${ }_{2} @ N C M S / S$ composite. Figure 6C was reproduced with permission from [48], Z. Yan et al. "A High-Kinetics Sulfur Cathode with a Highly Efficient Mechanism for Superior Room-Temperature Na-S Batteries", Adv. Mater., with permission from John Wiley and Sons Copyright ( 2020 WILEY-VCH Verlag GmbH \& Co. KGaA, Weinheim. This content is not subject to CC BY 4.0. (D) Schematic diagram on the catalytic mechanism of the VC-CNFs composite with $\mathrm{Na}_{2} \mathrm{~S}_{6}$. Figure 6D was reprinted from [12], Chemical Engineering Journal, vol. 395, by W. Tang, W. Zhong, Y. Wu, Y. Qi, B. Guo, D. Liu, S-J. Bao, M. Xu, "Vanadium carbide nanoparticles incorporation in carbon nanofibers for room-temperature sodium sulfur batteries: Confining, trapping, and catalyzing", article no. 124978. Copyright (2020), with permission from Elsevier. This content is not subject to CC BY 4.0. (E) Schematic representation of the interactions of $\mathrm{MnO}_{2}$ with different sodium polysulfides and polythionate complexes as well as the cycling performance of $\mathrm{CC} @ \mathrm{MnO}_{2} @ \mathrm{Na}_{2} \mathrm{~S}_{6}$ at $0.2 \mathrm{~A} \cdot \mathrm{g}^{-1}$. Figure 6E was reprinted from [51], Energy Storage Materials, vol. 20, by A. Kumar, A. Ghosh, A. Roy, M. R. Panda, M. Forsyth, D. R. MacFarlane, S. Mitra, "High-energy density room temperature sodium-sulfur battery enabled by sodium polysulfide catholyte and carbon cloth current collector decorated with $\mathrm{MnO}_{2}$ nanoarrays", pages no. 196-202. Copyright (2019), with permission from Elsevier. This content is not subject to CC BY 4.0 . 
$\mathrm{MnO}_{2}$ and long-chain polysulfides is not only electrostatic but also involves surface redox reactions. The polysulfides are oxidized to thiosulfate by $\mathrm{MnO}_{2}$ while $\mathrm{Mn}$ (IV) is reduced to $\mathrm{Mn}(\mathrm{III})$ and $\mathrm{Mn}(\mathrm{II})$. Afterwards, the formed thiosulfate interacts with long-chain polysulfides and converts them into shortchain polysulfides. The interactions between the metallic compound and the sulfur species are schematically shown in Figure 6E.

\section{Sulfur nanoparticles and nanostructures}

As described above, sulfur has become a very promising cathode material in RT alkali batteries due to its high theoretical capacity. Yet, sulfur in its bulk form presents severe obstacles to a more widespread use, especially in commercial alkali-sulfur batteries. The major electrochemical challenges of bulk sulfur are low electrical conductivity, large volume expansion on discharge $\left(\mathrm{S} \rightarrow \mathrm{Na}_{2} \mathrm{~S}\right.$ ), slow reaction kinetics with $\mathrm{Na}$, formation and loss of polysulfides due to the shuttle effect, low electrochemical utilization of sulfur, and low specific surface area $[16,52]$. Many of these drawbacks can be overcome by reducing the size of the active sulfur phase to the nanoparticle range. The accompanied increase in surface area generally accelerates interfacial reaction kinetics, NPs are more easily confined in conducting matrices, and the volume expansion of individual NPs is better distributed over the entire cathode improving its mechanical integrity [14].

There are different methods to incorporate sulfur nanoparticles and nanostructures in cathodes such as physical and chemical impregnation, mechanical mixing and self-assembly. Straightforward approaches are sulfur melt and vapor impregnation of suitable matrices. These routes require heating to temperatures above the melting $\left(115^{\circ} \mathrm{C}\right)$ and boiling $\left(446^{\circ} \mathrm{C}\right)$ point of sulfur, respectively. While the former methodology is more prone to generate rather thick and bulky sulfur layers, the latter can produce fine particles down to molecular sulfur species $\left(\mathrm{S}_{8}\right)$ deposited on and within porous host materials [53]. Many cathodes of $\mathrm{Na}-\mathrm{S}$ batteries are fabricated by the impregnation approach. In a recent work, $10 \mathrm{~nm} \mathrm{~S} \mathrm{NPs} \mathrm{were} \mathrm{synthesized} \mathrm{inside}$ carbon nanotubes by the melt diffusion method (Figure 7A) [54]. The resulting capacity of the $\mathrm{Na}-\mathrm{S}$ battery after 2500 cycles at $1 \mathrm{~A} \cdot \mathrm{g}^{-1}$ was $80 \mathrm{mAh} \cdot \mathrm{g}^{-1}$. Likewise, sulfur impregnation of hollow carbon nanocages rendered cathodes of $395 \mathrm{mAh} \cdot \mathrm{g}^{-1}$ at $1 \mathrm{~A} \cdot \mathrm{g}^{-1}$ for 850 cycles [45]. However, important issues are the need for elevated temperatures, working under sealed $\mathrm{Ar}$ or $\mathrm{N}_{2}$ conditions, and the possibly inhomogeneous sulfur distribution within the host material. Therefore, also ball milling is being employed to produce fine sulfur particles (tens of nanometers) from sulfur powder in the presence of graphene [55]. One advantage of this method over vapor impregnation routes is that it can yield very high sulfur loads of up to $90 \mathrm{wt} \%$ resulting in a high cathode capacity of $555 \mathrm{mAh} \cdot \mathrm{g}^{-1}$ at $5 \mathrm{C}[55]$.

Wet chemistry synthesis routes can also produce nanostructured sulfur. Lu et al. reported on the wet impregnation of carbon fiber cloth with sulfur dissolved in $\mathrm{CS}_{2}$ [56]. The process leads to sulfur deposition within the hollow lumen of the carbon fibers as well as on the external surface as thin film. A battery assembled with a metal $\mathrm{Na}$ anode had a capacity of $120 \mathrm{mAh} \cdot \mathrm{g}^{-1}$ after 300 cycles at $167 \mathrm{~mA} \cdot \mathrm{g}^{-1}$ current density. While $\mathrm{CS}_{2}$ is the most efficient solvent for sulfur, it is also an extremely reactive and hazardous solvent.

Therefore, more benign solution methods for the synthesis of $S$ NPs and sols are sought. In fact, such methods have been known for more than a hundred years now and can be distinguished in aqueous and organic solvent routes [57]. The so-called Weimarn sols are produced by dissolution of sulfur powder in ethanol or acetone-based solutions and the subsequent precipitation of sub-micrometer-size particles in water [57]. The so-called Raffo sols are obtained by a disproportionation reaction of $\mathrm{Na}_{2} \mathrm{~S}_{2} \mathrm{O}_{3}$ in presence of concentrated $\mathrm{H}_{2} \mathrm{SO}_{4}$ [57]. Raffo sols are stable, aqueous colloidal dispersions of $\mathrm{SO}_{3}{ }^{-}$-capped sulfur NPs in the $100-500 \mathrm{~nm}$ range and could be readily assembled with other compounds such as cathode materials. Yet, this fabrication route of sulfur cathodes appears to be highly underinvestigated despite the advantages an aqueous solution-based synthesis route can offer. Instead, commercial S NPs are increasingly employed in cathodes, for instance, by Chen et al. [58], who wrapped reduced graphene oxide sheets around such NPs (Figure 7B). In this case, the cathode was assembled in a Li battery that delivered $490 \mathrm{mAh} \cdot \mathrm{g}^{-1}$ after 500 cycles at $1 \mathrm{C}$.

It can be noticed that the concept of discrete S NPs is much more extensively researched in $\mathrm{Li}-\mathrm{S}$ batteries than in $\mathrm{Na}-\mathrm{S}$ batteries [59-61], which can be possibly explained by the longer history of Li battery research. Qu et al. [60] precipitated $15 \mathrm{~nm}$ sized $\mathrm{S} N P$ s on $\mathrm{V}_{2} \mathrm{O}_{5}$ by acid hydrolysis of $\mathrm{Na}_{2} \mathrm{~S}_{2} \mathrm{O}_{3}$. After encapsulation with graphene sheets the cathode had a discharge capacity of $215 \mathrm{mAh} \cdot \mathrm{g}^{-1}$ at $2 \mathrm{C}$ after 2000 cycles. In another chemical method, S NPs were precipitated on rGO from a deep eutectic solvent consisting of choline chloride and $\mathrm{Na}_{2} \mathrm{~S}_{2} \mathrm{O}_{3}$ [61]. This cathode material retained $900 \mathrm{mAh} \cdot \mathrm{g}^{-1}$ over 100 cycles. A modified precipitation method for S NPs is flash nanoprecipitation using a confined impingement jet mixer, in which $\mathrm{Na}_{2} \mathrm{~S}_{2} \mathrm{O}_{3}, \mathrm{H}_{2} \mathrm{O}, \mathrm{HCl}$, and a stabilizing copolymer (polyvinylpyrrolidone, PVP) form sub-micrometer-sized sulfur NPs within milliseconds [62]. The resulting sulfur-PVP composite cathode had a capacity of $808 \mathrm{mAh} \cdot \mathrm{g}^{-1}$ after 50 cycles at $0.1 \mathrm{C}$. 

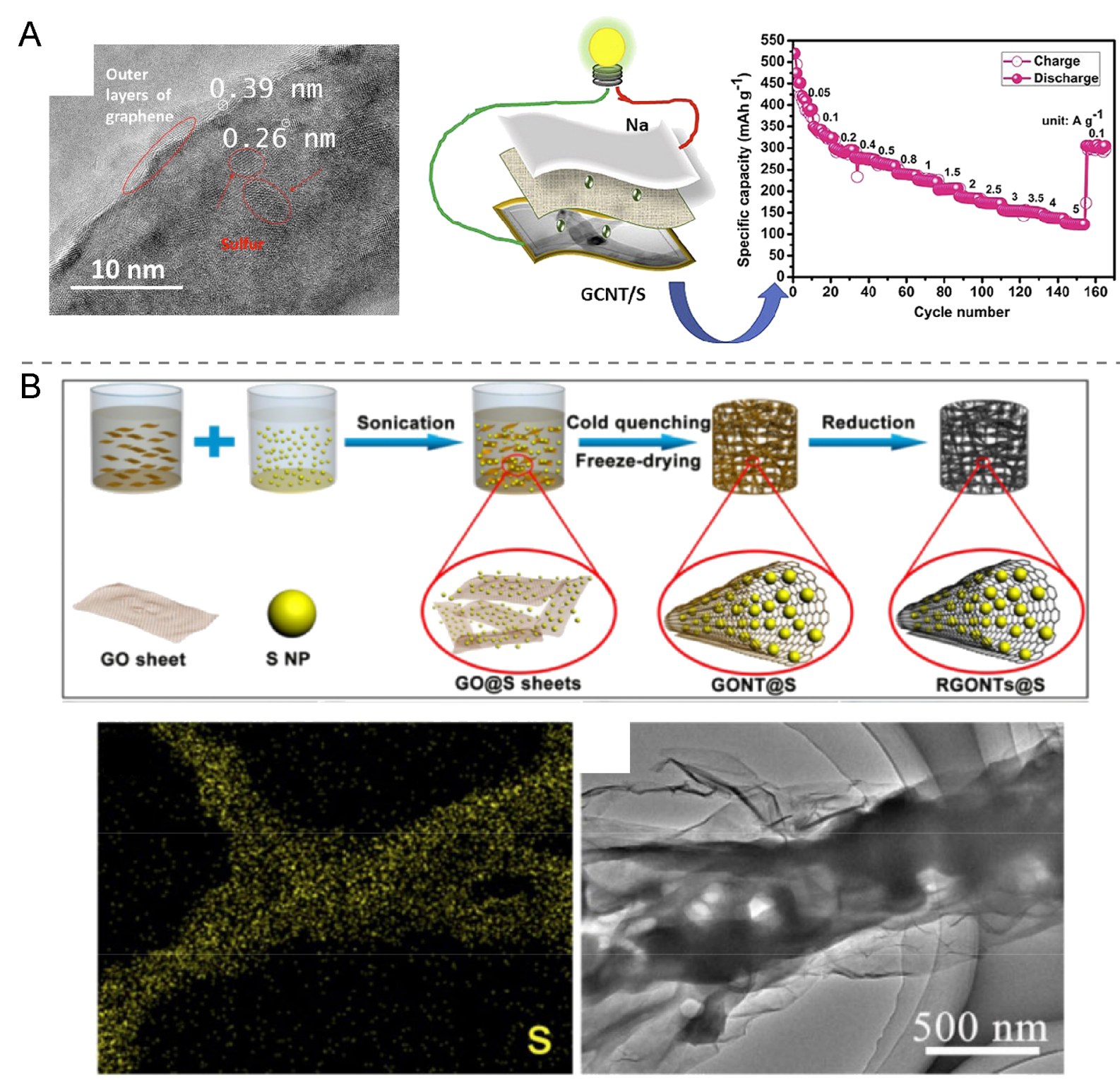

Figure 7: (A) HRTEM image of sulfur nanoparticles and graphene in GCNT/S and the cycle performance at $1 \mathrm{~A} \cdot \mathrm{g}^{-1}$. Figure $7 \mathrm{~A}$ was reprinted from [54], Journal of Alloys and Compounds, vol. 818, by A. P. V. K. Saroja, M. Kamaraj, S. Ramaprabhu, "Strongly coupled sulfur nanoparticles on graphene-carbon nanotube hybrid electrode for multifunctional sodium and aluminium ion storage", article no. 152864. Copyright (2020), with permission from Elsevier. This content is not subject to CC BY 4.0. (B) Schematic illustration of sulfur NPs assembled with reduced graphene oxide nanotubes and flexible films prepared of these (RGONTs@S).SEM/EDX elemental S map and TEM image of RGONTs@S. Figure 7B is from [58] and was reprinted by permission from Springer Nature from the journal Nano Research ("Sulfur nanoparticles encapsulated in reduced graphene oxide nanotubes for flexible lithium-sulfur batteries" by K. Chen, J. Cao, Q. Lu, Q. Wang, M. Yao, M. Han, Z. Niu, J. Chen). Copyright 2018 Springer Nature. This content is not subject to CC BY 4.0 .

\section{Sodium metal-free anodes}

The reason for the widespread use of metal $\mathrm{Na}$ anodes in $\mathrm{Na}-\mathrm{S}$ batteries is the very high capacity of $1165 \mathrm{mAh} \cdot \mathrm{g}^{-1}$ of metallic $\mathrm{Na}$ and the low reduction potential of $-2.71 \mathrm{~V}$ vs SHE. However, metallic $\mathrm{Na}$ is plagued by a range of severe drawbacks [63]. First of all, it is a very reactive element, which requires safe handling in inert atmosphere and storage in water-free petroleum. It can even react with aprotic solvents of electrolytes and compromise the performance and safety of the battery [64].
Other reasons for avoiding metal $\mathrm{Na}$ anodes are the pronounced dendrite formation and significant volume expansion and contraction during operation leading to performance loss $[19,65]$. Figure 8 illustrates the $\mathrm{Na}$ dendrite formation in the course of Na plating and stripping as the battery charges and discharges, respectively.

There are numerous strategies to mitigate the dendrite and reactivity issues of metal $\mathrm{Na}$ anodes. Amongst the most investigat- 
A

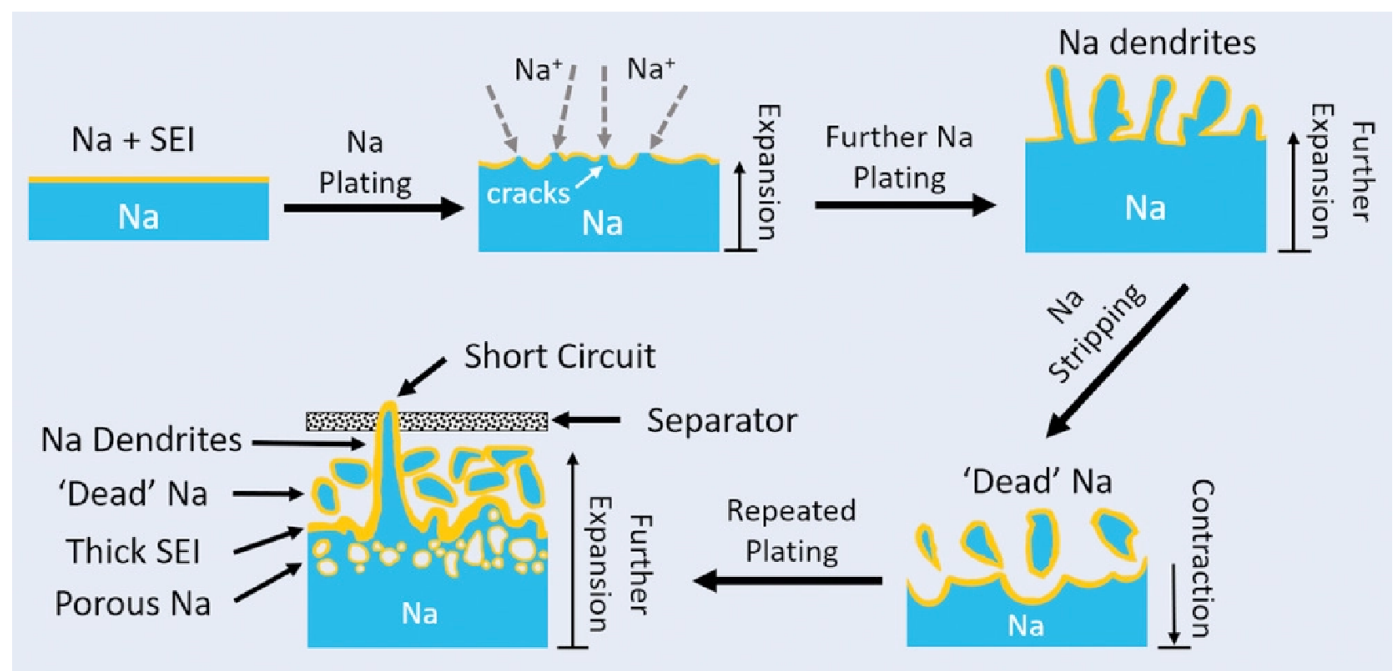

B

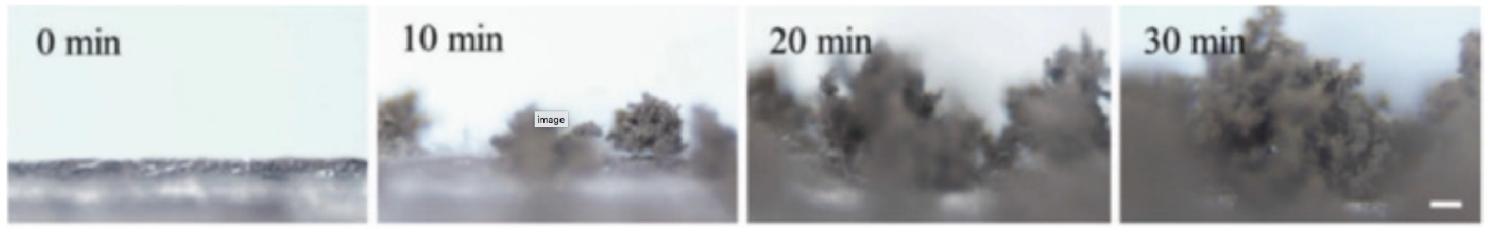

Figure 8: (A) Illustration of the $\mathrm{Na}$ dendrite formation mechanism during charging cycles, where $\mathrm{Na}$ is redeposited from $\mathrm{Na}^{+}$on the anode ( $\mathrm{Na}$ plating). The solid electrolyte interphase (SEI) formed on the $\mathrm{Na}$ anode is not capable of preventing the catastrophic dendrite growth. Figure $8 \mathrm{~A}$ was reproduced from [10] (@ 2019 B. Sun et al., published by WILEY-VCH Verlag GmbH \& Co. KGaA, Weinheim, distributed under the terms of the Creative Commons Attribution 4.0 International License, https://creativecommons.org/licenses/by/4.0). (B) Visualization of sodium dendrite growth in a carbonate electrolyte. Figure 8B was reprinted with permission from [65], X. Yang et al. "Anodes and Sodium-Free Cathodes in Sodium-lon Batteries", Adv. Energy Mater., with permission from John Wiley and Sons Copyright (C) 2020 WILEY-VCH Verlag GmbH \& Co. KGaA, Weinheim. This content is not subject to CC BY 4.0 .

ed approaches concerning the former are the controlled formation of protective solid electrolyte interphases (SEI) [66], while the latter is addressed by engineering of liquid and solid electrolytes [63]. Results show that these strategies have an undeniable positive influence on cycle stability and performance safety of sodium batteries [10]. Yet, there are currently also other strategies emerging that advocate metal $\mathrm{Na}$-free anodes. These can be divided in depositing nanometric $\mathrm{Na}$ on a porous host material and inserting $\mathrm{Na}$ ions in a suitable host material. Host materials for the deposition of $\mathrm{Na}$ are porous scaffolds based on carbon and metal. The insertion of $\mathrm{Na}$ ions can be performed with certain metals, semimetals, phosphorous, and carbon allotropes.

\section{Dispersed $\mathrm{Na}$ anodes}

In strict terms this approach is not $\mathrm{Na}$ metal-free as it relies on finely dispersed metallic $\mathrm{Na}$. But the small dimensions of the $\mathrm{Na}$ phase result in battery behavior distinct from macroscopic metal $\mathrm{Na}$ foil anodes. There are two fabrication methods of dispersed $\mathrm{Na}$ anodes. In one liquid $\mathrm{Na}$ is soaked into a porous scaffold, while in the other $\mathrm{Na}$ ions plate the porous host materi- al. An example of the former method is the use of carbonized wood, into the open pore system of which liquid $\mathrm{Na}$ is soaked (Figure 9A) [67]. Also, nanocarbon materials such as graphene and carbon aerogels, carbon microspheres, and mats, felts and papers based on carbon nanotubes and carbon fibers can also be efficiently soaked with $\mathrm{Na}$ and additionally provide bending and rolling flexibility, making them very attractive host materials [19,67-70].

$\mathrm{Na}$ can also be deposited in even finer structures by an electrochemical plating process. Herein, $\mathrm{Na}$ ions originating either from a metal $\mathrm{Na}$ electrode or from $\mathrm{Na}_{2} \mathrm{~S}$ /composite cathodes [27] are deposited on an electro-conductive host material, where they nucleate and grow into extended but nanometric $\mathrm{Na}$ coatings. For instance, Zhang et al. [69] used carbon fiber paper (CFP) to grow a $\mathrm{Na}$ layer from a metal $\mathrm{Na}$ electrode (Figure 9B). In the case of carbon hosts it needs to be kept in mind that $\mathrm{Na}^{+}$can also insert into the material as will be discussed further below. Therefore, the specific capacity of these electrodes depends on two mechanisms, the deposition/stripping of $\mathrm{Na}$ and the insertion/extraction of $\mathrm{Na}^{+}$. Metal scaffolds 

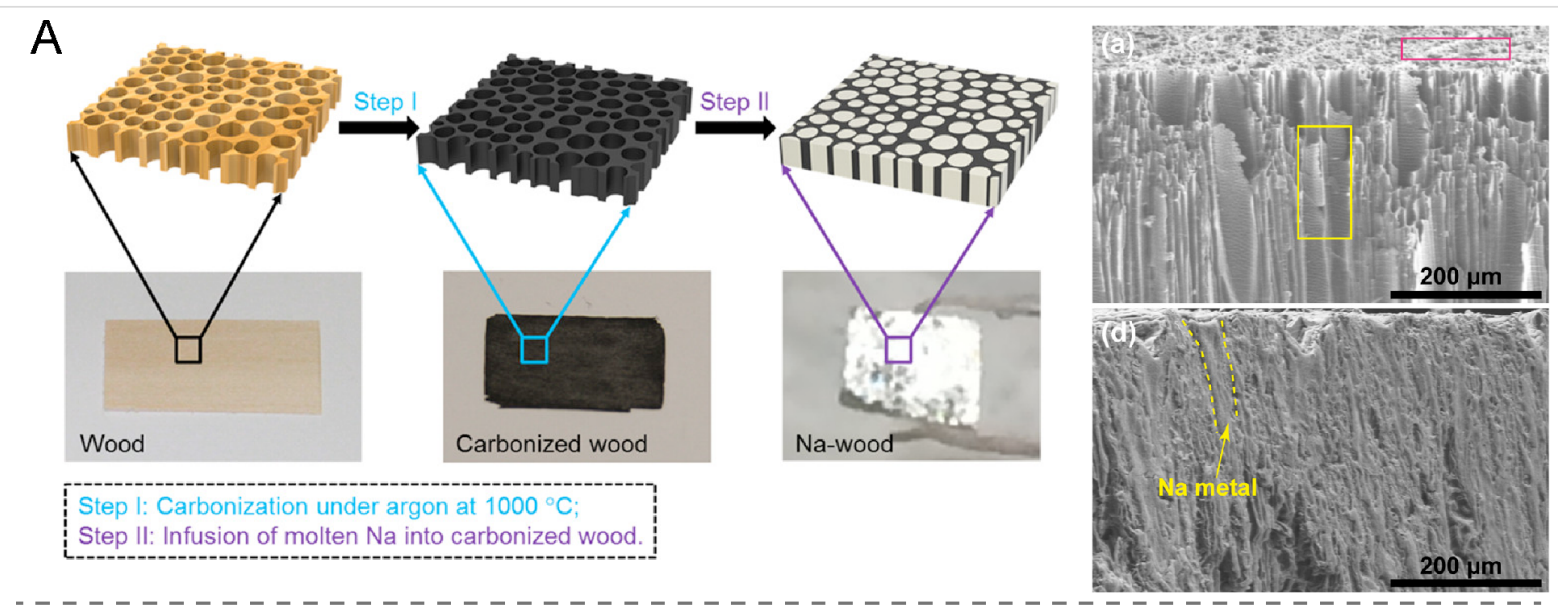

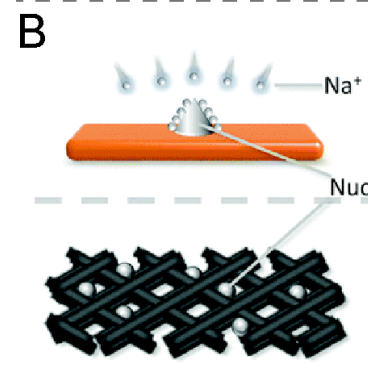

Nucleation
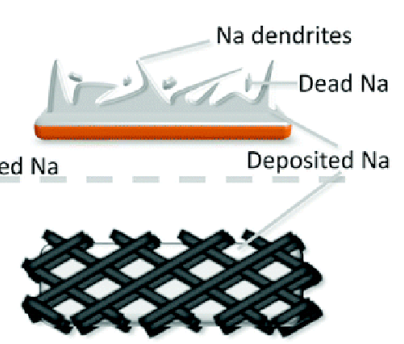

After cycles
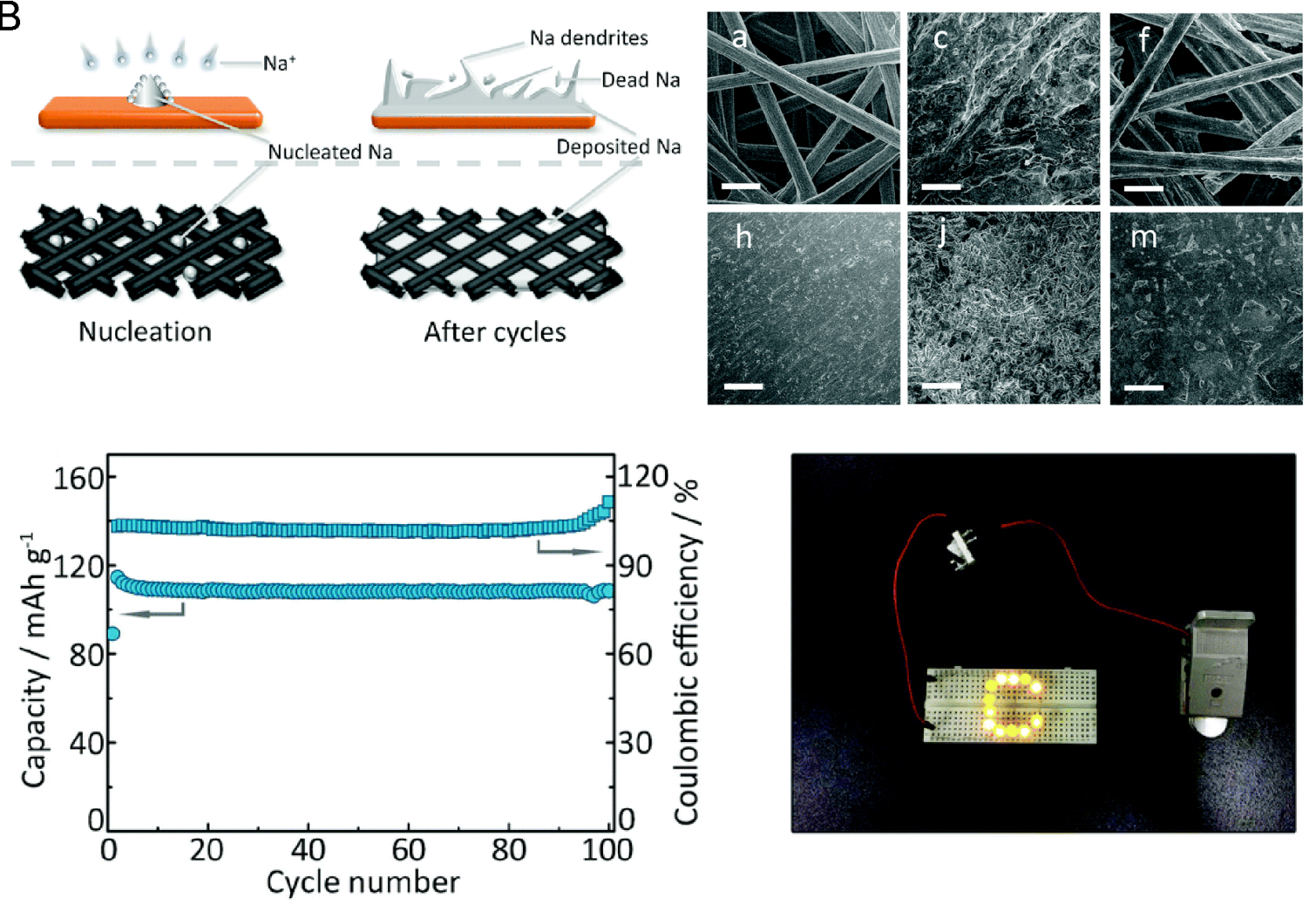

Figure 9: (A) Encapsulation of molten metallic Na into porous carbonized wood by a spontaneous infusion. SEM images of carbonized wood before and after melt infusion of metallic $\mathrm{Na}$ (yellow dotted line). Figure 9A was reprinted with permission from [67]. Copyright 2017, The American Chemical Society. (B) Schematic illustration of structural changes with Na depositing on $\mathrm{Cu}$ and CFP current collector during Na nucleation and growth. SEM images of Cu/CFP (upper row) and $\mathrm{Cu}$ (bottom row) after 30 plating/stripping cycles. The capacity and Coulombic efficiency of FeHCF with the CFP@Na anode. Figure 9B was reproduced from [69] with permission from the Chinese Chemical Society (CCS), Peking University (PKU), and the Royal Society of Chemistry. This content is not subject to CC BY 4.0.

and meshes fabricated from $\mathrm{Cu}, \mathrm{Ni}, \mathrm{Ni} @ \mathrm{Cu}$, or $\mathrm{Al}$ are other materials onto which $\mathrm{Na}$ can be plated. As shown in a recent work, porous $\mathrm{Ni}$ structures formed on $\mathrm{Cu}$ foil served as 3D current collector for plating $\mathrm{Na}$ [71]. Porous Al current collectors are also interesting $\mathrm{Na}$ plating substrates due to the lower weight and cost of $\mathrm{Al}$ compared to $\mathrm{Cu}$ and $\mathrm{Ni}$. The resultant $\mathrm{Al} / \mathrm{Na}$ anodes displayed high cycle stability (1000 cycles) with minimal Coulombic efficiency loss [72].
What is common to all these approaches is that finely dispersed $\mathrm{Na}$, even in its metallic $\mathrm{Na}$ form, suppresses dendrite formation to a significant extent. The generally reported reason for this observation is the more even distribution of Na nuclei, the greatly reduced concentration polarization, and a more robust SEI [19]. Further manifestations of the advantage of nanometric $\mathrm{Na}$ is the avoidance of a mechanic breakdown of the anode as the volume expansion and pore formation during 
plating/stripping is minimized in Na nanostructures. Eventual stresses are also significantly better distributed and accommodated by the matrices, especially in the case of flexible ones.

\section{$\mathrm{Na}$ alloys and intermetallics}

Sodium is capable of forming alloys and intermetallic compounds with a range of elements at room temperature, most notably with $\mathrm{Sb}, \mathrm{Sn}, \mathrm{P}, \mathrm{Si}, \mathrm{Ge}$, and $\mathrm{Bi}$ [73]. This way, considerable amounts of $\mathrm{Na}$ can be stored safely in intermetallic anodes, from which $\mathrm{Na}$ ions are reversibly released during discharging and charging processes. Among the most common alloying elements in SiBs are tin [74], antimony [75], and to a lesser degree phosphorous [76]. These elements can be either directly sodiated to form $\mathrm{Na}$ alloys or intermetallic compounds (M-Sn/Sb/P with $\mathrm{M}=\mathrm{Sn}, \mathrm{Sb}, \mathrm{P}, \mathrm{Si}, \mathrm{Bi}, \mathrm{Cu}, \mathrm{Ni}, \mathrm{Fe}, \mathrm{Zn}$ ).

Fully sodiated $\mathrm{Sb}, \mathrm{Sn}$, and $\mathrm{P}$ form the phases $\mathrm{Na}_{3} \mathrm{Sb}, \mathrm{Na}_{15} \mathrm{Sn}_{4}$, and $\mathrm{Na}_{3} \mathrm{P}$, which offer theoretical capacities of 660,847 and $2596 \mathrm{mAh} \cdot \mathrm{g}^{-1}$, respectively [73]. However, the measured values are usually somewhat lower due to cycle instability, slow sodiation kinetics, and SEI breakaway. The low cycle stability is caused by the considerable volume expansion in the range of $300-500 \%$ during sodiation of these elements, which threatens the integrity of the anode $[73,74,76]$. One solution to this drawback is down-sizing the active alloy to the nanometer scale in form of nanoparticles, nanorods, nanofibers, nanoarrays, and nanosheets, which are more tolerant to dilative stress $[75,76]$. In addition, these nanostructures can be incorporated into a flexible carbon matrix for further accommodation of mechanical strain (Figure 10A) [74,77]. The latter can be achieved, for instance, by electro-spinning of carbon-Sb nanofibers, which delivered up to $630 \mathrm{mAh} \cdot \mathrm{g}^{-1}$ at a rate of $\mathrm{C} / 15$ [78] (Figure 10B). Further examples are alloy/carbon nanocomposites consisting of $\mathrm{Sn} /$ graphene [79], Sb/graphene [80], Sn/carbon foams [79], red P/carbon aerogel [81] (Figure 10C), and Sn/ carbon spheres [79] with a capacity retention of $70-90 \%$ over $100-500$ cycles $[73,75,76]$.

Sodiation of intermetallic compounds ( $\mathrm{M}-\mathrm{Sn} / \mathrm{Sb} / \mathrm{P})$ is an interesting alternative as these intermetallic phases often show higher cycle stability than the pure elements and the respective alloys. This can be attributed to more effective mitigation mechanisms for the volume expansion [74]. Some intermetallic compounds also show higher capacities. For instance, a $\mathrm{Sb}$ anode with $7 \%$ of Si can reach a maximum capacity value as high as $663 \mathrm{mAh} \cdot \mathrm{g}^{-1}$ after 140 cycles in a $\mathrm{SiB}$, while the pure $\mathrm{Sb}$ anode delivered $625 \mathrm{mAh} \cdot \mathrm{g}^{-1}$ [26]. Also, silicon itself is also another promising material for sodium alloy anodes as its theoretical $\mathrm{Na}$ storage capacity of $954 \mathrm{mAh} \cdot \mathrm{g}^{-1}$ (NaSi phase) even exceeds the one of tin $\left(847 \mathrm{mAh} \cdot \mathrm{g}^{-1}\right)$ [26]. The low electrochemical reactivity and structural stability of crystalline bulk silicon during sodiation can be overcome by hybridation of nanosized $\mathrm{Si}$ with carbon fibers, after which Zhang et al. measured $200 \mathrm{mAh} \cdot \mathrm{g}^{-1}$ after 2000 cycles [83].

The investigation into phosphorous as anode material for $\mathrm{SiBs}$ is motivated by the highest capacity value of $\mathrm{P}\left(2596 \mathrm{mAh} \cdot \mathrm{g}^{-1}\right)$, which is even higher than that of metal $\mathrm{Na}$ [9]. However, also phosphorous anodes suffer from large volume expansion (up to $490 \%$ ), but in addition also from low electrical conductivity [76]. The use of amorphous (red) phosphorous can lessen the expansion problem and extend cycle life. For instance, a red phosphorous/graphene anode delivered $1095 \mathrm{mAh} \cdot \mathrm{g}^{-1}$ after 200 cycles at 1C [81]. It has also triggered research in a wider range of 2D materials as suitable and low-expansion anodes, starting with layered black phosphorous $[73,76]$. From there, exfoliated sheets of 2D allotropes came to scrutiny, such as antimonene, silicene, and phosphorene [73,83,84]. These sheets are usually integrated with graphene and other conducting carbon nanomaterials to afford mechanical support, flexibility, and electrical conductivity, which results in high capacity values (500-2000 $\mathrm{mAh} \cdot \mathrm{g}^{-1}$ ) over at least 100 cycles $[73,75,76,83]$.

The majority of the alloy anodes discussed in this section were tested and employed in sodium-ion batteries with diverse types of oxide and phosphate cathodes. However, they are now also increasingly incorporated in sodium-ion-sulfur batteries. Lee et al. were amongst the first to proof this concept by employing a sodiated $\mathrm{Sn}-\mathrm{C}$ anode and hollow $\mathrm{C}$ spheres infused with elemental sulfur as cathode [20]. The full cell rendered $550 \mathrm{mAh} \cdot \mathrm{g}^{-1}$ at $167 \mathrm{~mA} \cdot \mathrm{g}^{-1}$ within a $0.1-1.8 \mathrm{~V}$ voltage limit, albeit after 12 cycles the capacity dropped to $450 \mathrm{mAh} \cdot \mathrm{g}^{-1}$. Hence, there is much room for further investigation and improvement.

\section{Hard carbon anodes}

A somewhat more conventional approach to Na metal-free anodes is the use of hard carbon, also termed non-graphitizable carbon $[82,85]$. These are disorganized carbon materials with turbostratic nanoscale domains produced by pyrolysis of biomass, also including carbon black and other amorphous carbons. While $\mathrm{Na}^{+}$does not insert in graphite in contrast to $\mathrm{Li}^{+}$, hard carbon can store considerable amounts of sodium in the range of $300 \mathrm{mAh} \cdot \mathrm{g}^{-1}$ (Figure 10D) [82]. For their use in sodium batteries hard carbon materials can be pre-sodiated prior to the cell assembly. In a recent work, Liu et al. chemically presodiated hard carbon using sodium biphenyl [86]. The SiB full cell showed a discharge capacity of $100 \mathrm{mAh} \cdot \mathrm{g}^{-1}$ at $2 \mathrm{C}$ after 550 cycles (Figure 10E). Hard carbons can also be sodiated during the first charging cycle. Bloi et al. synthesized a porous $\mathrm{Na}_{2} \mathrm{~S} /$ carbon cathode, which they coupled with a hard carbon electrode [27]. During the initial charging, $\mathrm{Na}^{+}$plated the 

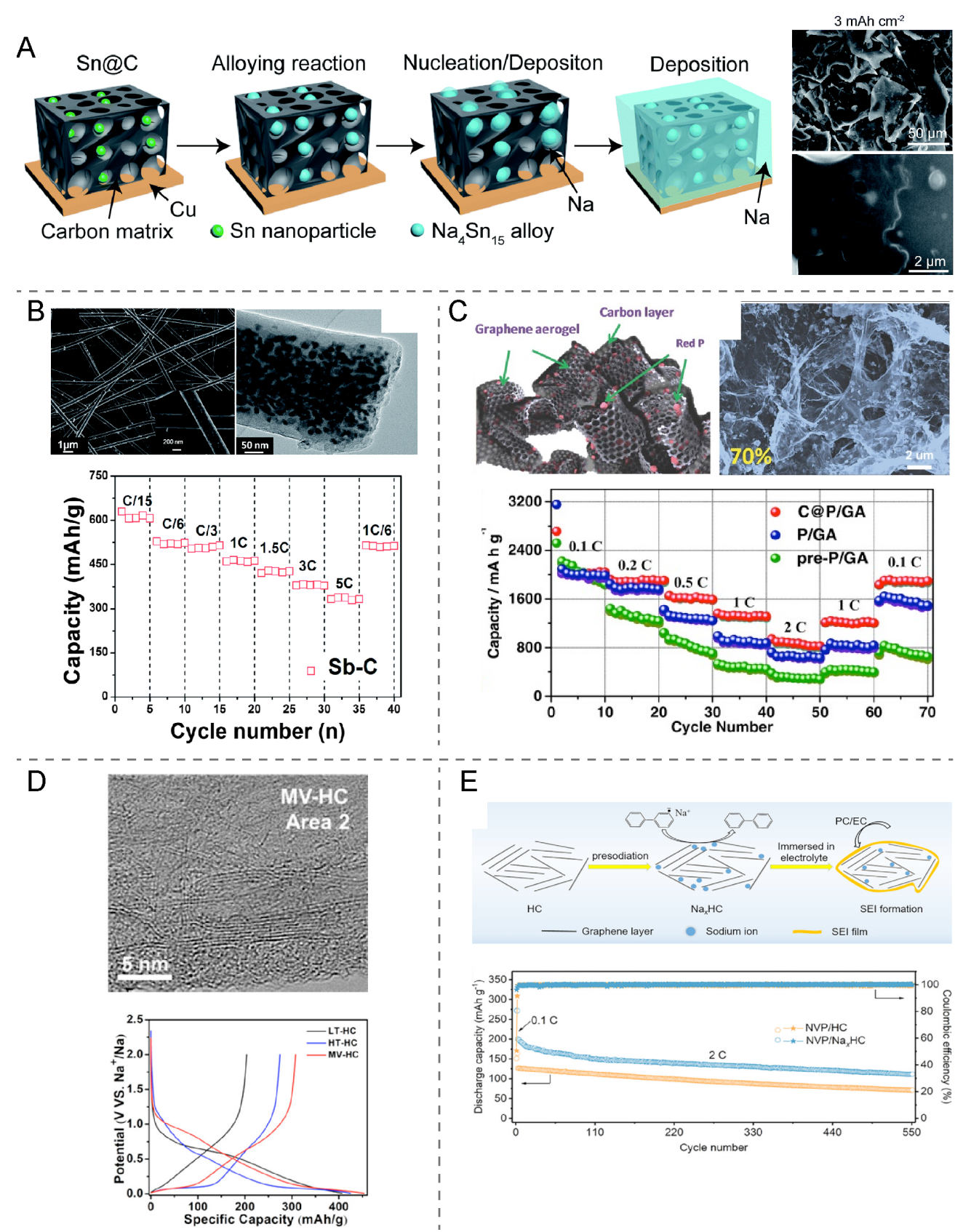

Figure 10: (A) Illustration of the sodiation process of a flexible Sn@C composite substrate and corresponding SEM images of the surface morphology upon Na plating with a current density of $2 \mathrm{~mA} \cdot \mathrm{cm}^{-2}$ and a capacity of $3 \mathrm{mAh} \cdot \mathrm{cm}^{-2}$. Figure $10 \mathrm{~A}$ was republished with permission of The Royal Society of Chemistry, from [77] ("Tin nanoparticles embedded in a carbon buffer layer as preferential nucleation sites for stable sodium metal anodes" H. Wang et. al., J. Mater. Chem. A, vol. 7, ( ) 2019); permission conveyed through Copyright Clearance Center, Inc. This content is not subject to CC BY 4.0. (B) SEM and TEM images of the Sb-C nanofibers and the C-rate capability at various current rates. Figure $10 \mathrm{~B}$ was republished with permission of The Royal Society of Chemistry, from [78] ("Sb-C nanofibers with long cycle life as an anode material for high-performance sodium-ion batteries" L. Wu et. al., Energy Environ. Sci., vol. 7, ( ) 2013); permission conveyed through Copyright Clearance Center, Inc. This content is not subject to CC BY 4.0. (C) Schematic illustration of the 3D porous graphene/red P composite (C@P/GA), a SEM image of the composite with 70\% of red $\mathrm{P}$ and the rate performance of the pre-P/GA, P/GA, and C@P/GA composites. Figure 10C was reproduced with permission from [81], H. Gao et al. "Integrated Carbon/Red Phosphorus/Graphene Aerogel 3D Architecture via Advanced Vapor-Redistribution for High-Energy Sodium-Ion Batteries", Adv. Energy Mater., with permission from John Wiley and Sons Copyright (C) 2016 WILEY-VCH Verlag GmbH \& Co. KGaA, Weinheim. This content is not subject to CC BY 4.0. (D) TEM image of MV-HC and first-cycle galvanostatic sodiation/desodiation potential profiles of three hard carbons at a current rate of $20 \mathrm{~mA} / \mathrm{g}$. Figure 10D was reprinted with permission from [82]. Copyright 2018, The American Chemical Society. This content is not subject to CC BY 4.0. (E) Schematic illustration of pre-sodiated hard carbon (HC) including a SEl layer and the long-term cycling performance of the full cell at a constant rate of $2 \mathrm{C}$. Figure $10 \mathrm{E}$ was reprinted with permission from [86]. Copyright 2020, The American Chemical Society. This content is not subject to CC BY 4.0 . 
hard carbon, which rendered a fully sodiated anode. The $\mathrm{Na}-\mathrm{S}$ full cell delivered $350 \mathrm{mAh} \cdot \mathrm{g}_{\mathrm{S}}{ }^{-1}$ in the first cycle and $130 \mathrm{mAh} \cdot \mathrm{g}_{\mathrm{S}}{ }^{-1}$ after ten cycles. This represents another example of successfully applying $\mathrm{Na}$ metal-free anode strategies for $\mathrm{RT} \mathrm{Na-S}$ batteries.

\section{Relevant recent patents on $\mathrm{RT} \mathrm{Na}-\mathrm{S}$ batteries}

Patents are a useful indicator for the innovation capacity of a scientific area and the potential commercialization of a technology. Therefore, this review includes a patent review on RT $\mathrm{Na}-\mathrm{S}$ batteries to assess the maturity of these devices and elucidate possible technology bottlenecks. An overview search in ESPACENET [87], the European Patent Office platform, with the term "sodium-battery" showed 1451 results, with a prominent increase in the number of documents produced in the last 10 years. It is interesting to note that the major applicant was Toyota Motor Company, alongside with other relevant companies, such as Nanotek Instruments, Samsung Electronics and General Electric. This emphasizes the relevance of applications and commercial use of the research in this area. The search results were reduced to half (703) and to a quarter (358) when "room-temperature" and additionally "sulfur or sulphur" were added to the search query, respectively, leaving the abovementioned companies still as the main applicants. The additional inclusion of the term "nanoparticle or nanoparticles" significantly reduced the number of documents to just 56. It is noteworthy that, in this case, the documents are all dated from the last decade and also that Nanotek Instrument is the only of the previous companies that remains involved, appearing as the most relevant applicant with 17 documents.

A closer revision of the patents reveals that just about 50 of them could be properly considered relevant to $\mathrm{Na}-\mathrm{S}$ batteries, though. In certain cases, the protected technology may also be applied to other types of batteries, typically lithium batteries. It is worth mentioning that most of the patents are in connection with companies, revealing the high importance of the topic from a technological and applicative point of view. The aspects covered by these patents ranged from the protection of complete devices to just covering specific materials and/or some components, mainly in relation to the electrodes. Table 2 collects information of some of the patents focused on the protection of devices. Most of these patents have been applied by Nanotek Instruments and include diverse designs of devices and processes for fabrication. The patents are very large in protecting the use of materials and components that may include a large variety of nanoparticles and nanomaterials, often related to the use of graphene and other nanoscale carbon materials as components of the electrode materials. A few patents

Table 2: Selection of patents protecting devices related to $\mathrm{RT} \mathrm{Na}-\mathrm{S}$ batteries and including nanotechnology aspects.

\begin{tabular}{|c|c|c|c|c|}
\hline $\begin{array}{l}\text { Patent publication } \\
\text { number/date (ref.) }\end{array}$ & Title & $\begin{array}{l}\text { Priorities/ } \\
\text { Applicant }\end{array}$ & Area & Nanotechnology-related content \\
\hline $\begin{array}{l}\text { WO2017048341A1/ } \\
2017-03-23[88]\end{array}$ & $\begin{array}{l}\text { Alkali metal or } \\
\text { alkali-ion batteries } \\
\text { having high } \\
\text { volumetric and } \\
\text { gravimetric energy } \\
\text { densities }\end{array}$ & $\begin{array}{l}\text { 2015-09-14/ } \\
\text { B. Z. Jang, } \\
\text { Nanotek } \\
\text { Instruments } \\
\text { Inc. \& A. } \\
\text { Zhamu }\end{array}$ & $\begin{array}{l}\text { Alkali metal-ion battery, } \\
\text { comprising an anode and cathode } \\
\text { having the anode and cathode } \\
\text { active material dispersed in a } \\
\text { liquid electrolyte disposed in pores } \\
\text { of a 3D porous anode/cathode } \\
\text { current collector; and a separator } \\
\text { disposed between the anode and } \\
\text { the cathode }\end{array}$ & $\begin{array}{l}\text { Components of the electrodes } \\
\text { may include nanoparticles and } \\
\text { diverse types of nanostructured } \\
\text { materials (nanowires, nanodiscs, } \\
\text { nanoribbons, nanoplatelets, } \\
\text { nanocoatings, or nanosheets), for } \\
\text { instance, graphene }\end{array}$ \\
\hline $\begin{array}{l}\text { WO2017055678A1/ } \\
2017-04-06 \text { [89] }\end{array}$ & $\begin{array}{l}\text { Electrochemical } \\
\text { secondary cells for } \\
\text { high-energy or } \\
\text { high-power battery } \\
\text { use }\end{array}$ & $\begin{array}{l}2015-09-30 / \\
\text { Broadbit } \\
\text { Batteries OY }\end{array}$ & $\begin{array}{l}\text { Electrochemical cell for a } \\
\text { secondary battery, preferably for } \\
\text { use in an electric vehicle }\end{array}$ & $\begin{array}{l}\text { The electrochemical cell includes } \\
\text { a cathode and an anode and an } \\
\text { electrolyte that includes one or } \\
\text { more nitrogen-containing sol } \\
\text { precursors and a salt comprising } \\
\text { sodium, and in which the cathode } \\
\text { material may contain diverse } \\
\text { carbon nanoparticles }\end{array}$ \\
\hline $\begin{array}{l}\text { WO2017123544A1/ } \\
2017-07-20[90]\end{array}$ & $\begin{array}{l}\text { Alkali metal-sulfur } \\
\text { batteries having } \\
\text { high volumetric and } \\
\text { gravimetric energy } \\
\text { densities }\end{array}$ & $\begin{array}{l}\text { 2016-01-15/ } \\
\text { B. Z. Jang, } \\
\text { Nanotek } \\
\text { Instruments } \\
\text { Inc., Z. } \\
\text { Aruna }\end{array}$ & $\begin{array}{l}\text { Design of alkali metal (Li or } \\
\text { Na)-sulfur battery, wherein the } \\
\text { active cathode material is } \\
\text { dispersed in an electrolyte and a } \\
\text { conductive porous structure acting } \\
\text { as a 3D scaffold }\end{array}$ & $\begin{array}{l}\text { Description of the battery where } \\
\text { the active cathode material is } \\
\text { sulfur, polysulfide, sulfur-polymer } \\
\text { composite, sulfur-carbon } \\
\text { composite, sulfur-graphene } \\
\text { composite, or a combination } \\
\text { thereof }\end{array}$ \\
\hline
\end{tabular}


Table 2: Selection of patents protecting devices related to RT Na-S batteries and including nanotechnology aspects. (continued)

WO2017123546A1/ Method of 2017-07-20 [91] producing alkali metal or alkali-ion batteries having high volumetric and gravimetric energy densities

\begin{tabular}{|c|c|}
\hline $\begin{array}{l}\text { WO2017149204A2/ } \\
2017-09-08 \text { [92] }\end{array}$ & $\begin{array}{l}\text { Rechargeable } \\
\text { sodium cells for } \\
\text { high energy densi } \\
\text { battery use }\end{array}$ \\
\hline $\begin{array}{l}\text { WO2018118800A1/ } \\
2018-06-28 \text { [93] }\end{array}$ & $\begin{array}{l}\text { Flexible and } \\
\text { shape-conformal } \\
\text { cable-type alkali } \\
\text { metal batteries }\end{array}$ \\
\hline
\end{tabular}

WO2018208660A1/ Rolled alkali metal 2018-11-15 [94] batteries and production process

WO2018217274A1/ Alkali metal battery 2018-11-29 [95]

having a deformable

quasi-solid electrode material

WO2018222348A1/ Shape-conformable 2018-12-06 alkali metal battery having a conductive and deformable quasi-solid polymer electrode
2016-01-15/ Process for producing an alkali

B. Z. Jang, metal battery, comprising multiple Nanotek conductive porous layers, multiple Instruments wet anode layers of an active Inc. \& A. anode material mixed with a liquid Zhamu electrolyte, and multiple wet cathode layers of an active cathode material mixed with a liquid electrolyte; stacking and consolidating a desired number of the porous layers and a desired number of wet anode/cathode layers to form an anode/cathode electrode; placing a porous separator layer in contact with the electrode and assembling all the components to produce the battery

2016-03-04/ Electrochemical cell for an Broadbit energy-dense rechargeable Batteries oY battery, including a solid metallic sodium anode

2016-12-20/ A cable-shaped alkali metal Nanotek battery consisting of an electrode Instruments (a porous rod), a porous separator Inc.

wrapped around, a second electrode wrapped around or encasing the porous separator, and a protective casing or packing tube wrapping

2017-05-08 Protect a rolled alkali metal (Li,

\& $\mathrm{Na}, \mathrm{K}$ ) battery that comprises an 2017-11-20/ anode, a cathode, an alkali metal Nanotek ion-conducting separator, and an Instruments alkali metal ion-containing Inc. electrolyte in ionic contact with the anode and the cathode, wherein the anode and cathode contain a wound roll of an electrode active material substantially perpendicular to the separator plane

2017-05-24/ Alkali metal cell having a Nanotek quasi-solid electrode, by Instruments combining a quantity of an active Inc. material, a quantity of an electrolyte, and a conductive additive to form a deformable and electrically conductive electrode material containing conductive filaments, forms a 3D network of electron-conducting pathways that can be deformed into an electrode shape without interrupting the 3D network pathways

2017-05-30 Method of preparing an alkali $\&$ $2017-05-31 /$ Nanotek electrode material, containing Instruments conductive filaments included into Inc.
Components of the electrodes may include nanoparticles and diverse types of nanostructured materials (nanowires, nanodiscs, nanoribbons, nanoplatelets, nanocoatings, or nanosheets), for instance, graphene

Description of a sodium rechargeable high energy density battery that includes the use of $\mathrm{SO}_{2}$ in the electrolyte

Components of the electrodes may include nanoparticles and diverse type of nanostructured materials (nanowires, nanodiscs, nanoribbons, nanoplatelets, nanocoatings, or nanosheets), for instance, hollow carbon nanowires or graphene

The composition of the electrode materials may include diverse types of nanoparticles including graphene

The conductive filaments are selected from carbon nanofibers, graphite nanofibers, carbon nanotubes, metal nanowires, amongst other nanoparticles. Additionally, other elements of the cell may also contain diverse types of nanoparticles or nanostructured materials

Components in the electrodes may include nanoparticles and diverse types of nanostructured materials (nanowires, nanodiscs, nanoribbons or nanoplatelets, nanocoatings, or nanosheets), for instance, hollow carbon nanotubes 
Table 2: Selection of patents protecting devices related to RT Na-S batteries and including nanotechnology aspects. (continued)

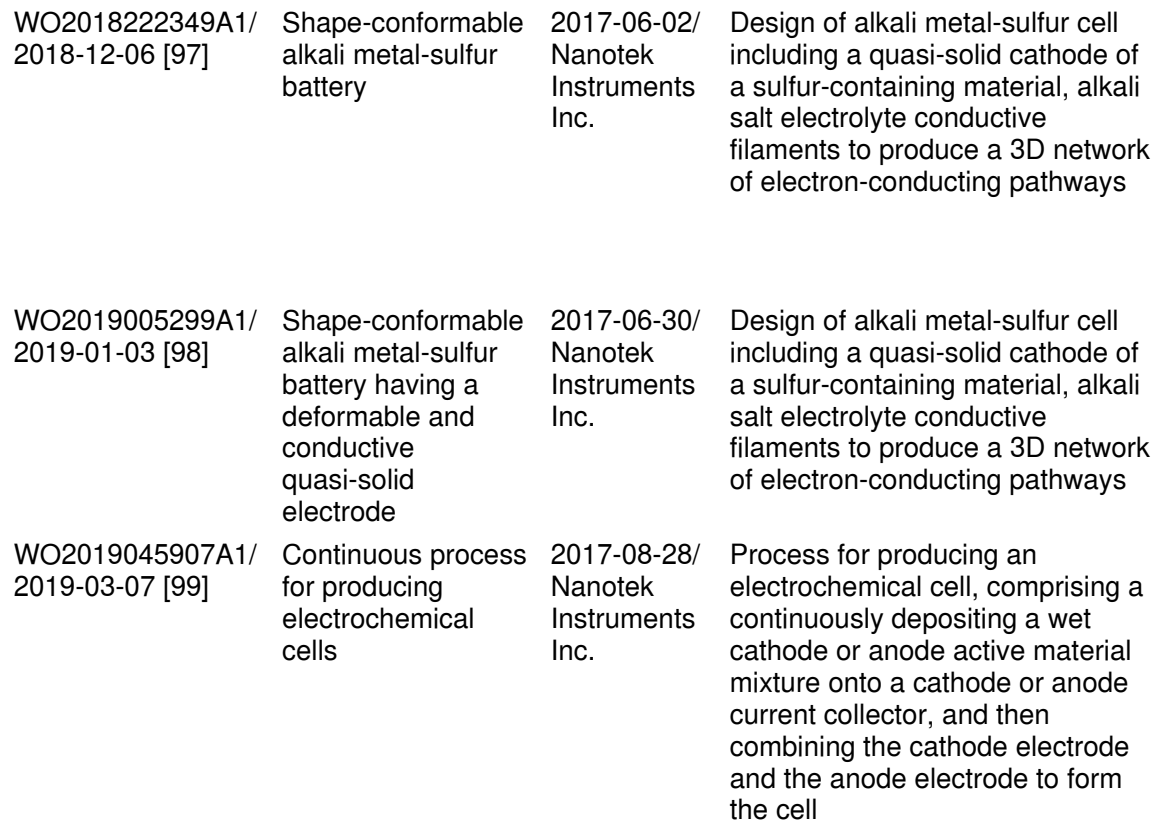

2017-06-30/

Nanotek

Design of alkali metal-sulfur cell Inc. a sulfur-containing material, alkali salt electrolyte conductive filaments to produce a 3D network of electron-conducting pathways

2017-08-28/ Process for producing an Nanotek Instruments Inc. electrochemical cell, comprising a continuously depositing a wet cathode or anode active material mixture onto a cathode or anode current collector, and then combining the cathode electrode and the anode electrode to form the cell

The composition of the elements of the battery includes the use of diverse nanomaterials and nanostructured materials, for instance, the use of conductive filaments such as carbon nanotubes, carbon nanofibers, nanostructured or porous disordered carbon materials

Use of conductive filaments such as carbon nanofibers, carbon nanotubes, metal nanowires, graphene, and others
The anode active material contains an alkali intercalation compound selected from hollow carbon nanowires, amongst other carbonaceous materials are also from Broadbit Batteries OY. In this case, applications related to electrical vehicles were the main focus.

A large part of the patents protects certain elements of the battery electrodes (Table 3). Some of the patents protect the production of specific materials for application as electrode, in- cluding the production and/or use of different types of nanoparticles, such as oxides and carbonaceous materials that can be incorporated into the anode and/or cathode material to increase the efficiency. In other cases, patents also include aspects dealing with the construction of electrodes, in which the design of precise structures, for instance, 3D networks, favors the pres-

Table 3: Selection of representative patents dealing with RT Na-S batteries and nanoparticles and nanotechnology, which protect aspects related to the electrodes.

\begin{tabular}{|c|c|c|c|c|}
\hline $\begin{array}{l}\text { Patent publication } \\
\text { number (ref.) }\end{array}$ & Title & $\begin{array}{l}\text { Priority/ } \\
\text { Applicant }\end{array}$ & Area & $\begin{array}{l}\text { Nanotechnology-related } \\
\text { content }\end{array}$ \\
\hline $\begin{array}{l}\text { WO2012128262A1/ } \\
2012-09-27 \text { [100] }\end{array}$ & $\begin{array}{l}\text { Sodium secondary } \\
\text { cell electrode and } \\
\text { sodium secondary } \\
\text { cell }\end{array}$ & $\begin{array}{l}2011-03-24 \text { \& } \\
2011-10-12 / \\
\text { T. Ishikawa; S. } \\
\text { Komaba; S. Kuze; } \\
\text { Y. Matsuura; W. } \\
\text { Murata; Sumitomo } \\
\text { Chemical Co.; Univ. } \\
\text { Tokyo Science } \\
\text { Education Found \& } \\
\text { N. Yabuuchi }\end{array}$ & $\begin{array}{l}\text { Sodium secondary cell } \\
\text { electrode contains tin powder } \\
\text { as an electrode active material } \\
\text { and other forming agents of } \\
\text { polymeric type }\end{array}$ & $\begin{array}{l}\text { Sn particles can be of } \\
\text { nanometric size }\end{array}$ \\
\hline $\begin{array}{l}\text { WO2012151094A2/ } \\
2012-11-08 \text { [101] }\end{array}$ & $\begin{array}{l}\text { Composite } \\
\text { materials for battery } \\
\text { applications }\end{array}$ & $\begin{array}{l}\text { 2011-05-04/ } \\
\text { A. Abouimrane, K. } \\
\text { Amine, J. Ren, } \\
\text { UChicago Argonne } \\
\text { LLC, J. Yang }\end{array}$ & $\begin{array}{l}\text { A process for producing } \\
\text { nanocomposite materials for } \\
\text { use in batteries includes } \\
\text { electroactive materials are } \\
\text { incorporated within a } \\
\text { nanosheet host material }\end{array}$ & $\begin{array}{l}\text { A gaseous electroactive } \\
\text { material precursor interacts } \\
\text { with a carbonaceous, } \\
\text { exfoliated nanosheet material } \\
\text { to form a nanocomposite } \\
\text { material, including the use of } \\
\text { graphene as exfoliated } \\
\text { nanosheet carbonaceous } \\
\text { material }\end{array}$ \\
\hline
\end{tabular}


Table 3: Selection of representative patents dealing with RT Na-S batteries and nanoparticles and nanotechnology, which protect aspects related to the electrodes. (continued)

$\begin{array}{ll}\text { WO2014083135A1/ } & \begin{array}{l}\text { Tin-based anode } \\ \text { material for a } \\ \text { rechargeable } \\ \text { battery and } \\ \text { preparation method }\end{array} \\ \text { US10320000B2/ } & \begin{array}{l}\text { Pyrolytic carbon } \\ \text { black composite } \\ \text { and method of } \\ \text { making the same }\end{array} \\ \text { US2017155140A1/ } & \begin{array}{l}\text { Antimony-based } \\ \text { anode material for } \\ \text { re17-06-01 [104] }\end{array} \\ & \begin{array}{l}\text { rechargeable } \\ \text { batteries and } \\ \text { preparation method }\end{array} \\ \text { WO2017062197A1/ } & \begin{array}{l}\text { Continuous process } \\ \text { for producing } \\ \text { electrodes and }\end{array} \\ & \begin{array}{l}\text { alkali metal } \\ \text { batteries having } \\ \text { ultra-high energy } \\ \text { densities }\end{array} \\ & \end{array}$

2016-02-29/
WO2017172044A2/ Pyrolytic carbon 2017-10-05 [103] black composite and method of making the same

US2019270678A1/ New process for 2019-09-05 [106] producing highly carbonaceous materials and the highly

carbonaceous material obtained

WO2019108343A1/ Anode particulates 2019-06-06 [107] or cathode particulates and alkali metal batteries containing same
UT-Battelle LLC

2016-10-28 \&

2017-10-26/

Arkema France

2017-11-30 \& 2017-12-05/ Nanotek Instruments Inc.
Method for preparing sulfonated-carbon material for using in electrodes of lithium-ion or sodium-ion battery

Process for the production of highly carbonaceous material including steps of carbonization of fibers covered with a cyclic organic or aromatic compound to produce a highly carbonaceous material of possible application in alkali batteries

Electrodes, anode and cathode based on the combination of components forming a three dimensional network of electron-conducting pathways in contact with the electrode active material

Electrode material based on the combination of components forming a three dimensional network of electron-conducting pathways

alkali metal batteries containing same

US10873083B2/ 2020-12-22 [109]
Anode particulates or cathode alkali metal batteries particulates and
2017-11-30/

Nanotek Instruments Inc. \& Global Graphene Group Inc.

2017-11-30 \& 2018-01-02/ Global Graphene Group Inc.
Anode and cathode including nanoparticles for an alkali metal battery where the particulate can be of any shape, but preferably spherical or ellipsoidal in shape
Development of tin mixed oxides nanoparticles for using as anode in sodium batteries

The carbon source to produce the electrode material includes carbon reinforcing agents that may consist of carbon nanoparticles

Development of antimony mixed oxides nanoparticles for using as anode in sodium batteries

The method includes various steps: continuously feeding an electrically conductive porous layer to an anode or cathode material impregnation zone, impregnating a wet anode or cathode active material mixture to form an anode or cathode electrode, and supplying a protective film to cover the electrode

The carbon source to produce the electrode material includes carbon reinforcing agents that may consist of carbon nanoparticles

The precursors and reagents used to produce the highly carbonaceous material include nanocellulose and diverse carbonaceous nanofillers

(n)


Table 3: Selection of representative patents dealing with RT Na-S batteries and nanoparticles and nanotechnology, which protect aspects related to the electrodes. (continued)

\begin{tabular}{|c|c|c|c|c|}
\hline $\begin{array}{l}\text { US2019173079A1/ } \\
2019-06-06 \text { [110] }\end{array}$ & $\begin{array}{l}\text { Method of } \\
\text { producing } \\
\text { participate } \\
\text { electrode materials } \\
\text { for alkali metal } \\
\text { batteries }\end{array}$ & $\begin{array}{l}2017-12-05 \& \\
2018-01-02 / \\
\text { Nanotek } \\
\text { Instruments Inc. }\end{array}$ & $\begin{array}{l}\text { Method of producing anode or } \\
\text { cathode particulates for an } \\
\text { alkali metal battery }\end{array}$ & $\begin{array}{l}\text { The method is characterized } \\
\text { for converting a said slurry into } \\
\text { multiple anode/cathode } \\
\text { particulates having dimensions } \\
\text { on the nano/microscale }\end{array}$ \\
\hline $\begin{array}{l}\text { US10797313B2/ } \\
\text { 2020-10-06 [111] }\end{array}$ & $\begin{array}{l}\text { Method of } \\
\text { producing anode or } \\
\text { cathode } \\
\text { particulates for } \\
\text { alkali metal } \\
\text { batteries }\end{array}$ & $\begin{array}{l}2017-12-05 / \\
\text { Nanotek } \\
\text { Instruments Inc. \& } \\
\text { Global Graphene } \\
\text { Group Inc. }\end{array}$ & $\begin{array}{l}\text { Method of producing anode or } \\
\text { cathode particulates for an } \\
\text { alkali metal battery including } \\
\text { particles of the active material, } \\
\text { the electron-conducting } \\
\text { material forming a 3D network, } \\
\text { and an electrolyte }\end{array}$ & $\begin{array}{l}\text { The combination of particulate } \\
\text { components implies the use of } \\
\text { pan-coating, air-suspension } \\
\text { coating, centrifugal extrusion, } \\
\text { vibration nozzle, spray-drying, } \\
\text { interfacial polycondensation or } \\
\text { interfacial cross-linking, in situ } \\
\text { polymerization, matrix } \\
\text { polymerization methodos, or a } \\
\text { combination thereof }\end{array}$ \\
\hline $\begin{array}{l}\text { WO2019135827A1/ } \\
2019-07-11 \text { [112] }\end{array}$ & $\begin{array}{l}\text { Anode particulates } \\
\text { or cathode } \\
\text { particulates for } \\
\text { alkali metal } \\
\text { batteries }\end{array}$ & $\begin{array}{l}\text { 2018-01-02/ } \\
\text { Nanotek } \\
\text { Instruments Inc. }\end{array}$ & $\begin{array}{l}\text { Electrode, anode and cathode, } \\
\text { materials formed of particles of } \\
\text { the electrode material, an } \\
\text { electron-conducting material, } \\
\text { and an alkali salt with an } \\
\text { optional polymer or its } \\
\text { monomer, but without a liquid } \\
\text { solvent, forming a 3D network } \\
\text { of electron-conducting } \\
\text { pathways, for sodium and } \\
\text { lithium battery applications }\end{array}$ & $\begin{array}{l}\text { The particulate electrode } \\
\text { material may contain } \\
\text { components as nanoparticles, } \\
\text { nanowires, nanofibers, } \\
\text { nanotubes, nanosheets, } \\
\text { nanobelts, nanoribbons, } \\
\text { nanodiscs, nanoplatelets, or } \\
\text { nanohorns having a thickness } \\
\text { or diameter from } 0.5 \mathrm{~nm} \text { to } \\
100 \mathrm{~nm} \text {, and it could also } \\
\text { include graphene as } \\
\text { electron-conducting } \\
\text { component }\end{array}$ \\
\hline $\begin{array}{l}\text { CN109437123A/ } \\
2019-03-08 \text { [113] }\end{array}$ & $\begin{array}{l}\text { Selenium-doped } \\
\text { ferrous disulfide } \\
\text { carbon-coated } \\
\text { composite material } \\
\text { and preparation } \\
\text { and application } \\
\text { methods thereof }\end{array}$ & $\begin{array}{l}\text { 2018-10-16/ } \\
\text { Zhongshan } \\
\text { Gaorong New } \\
\text { Energy Tech. Co. } \\
\text { Ltd. }\end{array}$ & $\begin{array}{l}\text { Preparation and application } \\
\text { methods of selenium-doped } \\
\text { ferrous disulfide carbon-coated } \\
\text { composite material }\end{array}$ & $\begin{array}{l}\text { Application of a } \\
\text { selenium-doped ferrous } \\
\text { disulfide carbon-coated } \\
\text { composite as a negative } \\
\text { electrode material in } \\
\text { sodium-ion batteries }\end{array}$ \\
\hline
\end{tabular}

ence of specific conducting pathways that improve the performance of the electrode. Again, a large number of these patents were applied by companies from different industry fields.

Finally, Table 4 includes several patents selected as representative examples of other protected items of interest related to $\mathrm{Na}-\mathrm{S}$ batteries. For instance, the development of polymer elec- trolytes, additives, salts, or specific materials that can be used in the preparation of components and conformation of elements of the battery.

The analysis of the patent search results clearly shows a lack of specific patents dealing with the production of cathode materials involving sulfur nanoparticles or anodes consisting of nano-

Table 4: Other patents of interest related to RT Na-S batteries.

\begin{tabular}{|c|c|c|c|c|}
\hline $\begin{array}{l}\text { Patent publication } \\
\text { number (ref.) }\end{array}$ & Title & $\begin{array}{l}\text { Priority/ } \\
\text { Applicant }\end{array}$ & Area & Relevance for $\mathrm{Na}-\mathrm{S}$ batteries \\
\hline $\begin{array}{l}\text { EP3422438A1/ } \\
2019-01-02 \text { [114] }\end{array}$ & $\begin{array}{l}\text { Solid polymer } \\
\text { electrolyte based on } \\
\text { modified cellulose and } \\
\text { its use in lithium or } \\
\text { sodium secondary } \\
\text { batteries }\end{array}$ & $\begin{array}{l}\text { 2017-06-28/ } \\
\text { Fundación Centro } \\
\text { de Investigación } \\
\text { Cooperativa de } \\
\text { Energías } \\
\text { Alternativas CIC } \\
\text { Energigune } \\
\text { Fundazioa }\end{array}$ & $\begin{array}{l}\text { Solid polymer electrolyte } \\
\text { based on modified cellulose } \\
\text { incorporating by covalent } \\
\text { grafting the anion of an } \\
\text { organic sodium salt or lithium } \\
\text { salt }\end{array}$ & $\begin{array}{l}\text { Alternative polymer } \\
\text { electrolyte for application in } \\
\text { batteries }\end{array}$ \\
\hline
\end{tabular}


Table 4: Other patents of interest related to $\mathrm{RT} \mathrm{Na}-\mathrm{S}$ batteries. (continued)

$\begin{array}{ll}\text { W02019010474A1/ } & \text { Electrospinning of } \\ \text { PVDF-HFP: novel } \\ \text { composite polymer } \\ \text { electrolytes (CPES) } \\ \text { with enhanced ionic } \\ \text { conductivities for } \\ \text { lithium-sulfur batteries } \\ \text { US2020251781A1/ } & \begin{array}{l}\text { Non-aqueous } \\ \text { electrolytes for } \\ \text { electrochemical cells }\end{array}\end{array}$

WO2020006642A1/ Glycidyl-containing 2020-01-09 [117] polymers, polymer compositions comprising them and their use in electrochemical cells

US2014205883A1/ Reactive separator for 2014-07-24 [118] a metal-ion battery

KR102001454B1/ 2019-07-18 [119]

The preparation method of multi-layer core-shell nano particles comprising porous carbon shell and core-shell nano particles thereby

WO2013073259A1/ High-purity parastyrene 2013-05-23 [120] sulfonic acid (salt); polystyrene sulfonic acid (salt) using same; dispersant, conductive polymer dopant, aqueous nanocarbon material dispersion and aqueous conductive polymer dispersion each using polystyrene sulfonic acid (salt); and method for producing polystyrene sulfonic acid (salt)

CN111517374A/ Preparation method of 2020-08-11 [121] $\quad \mathrm{Fe}_{7} \mathrm{~S}_{8} / \mathrm{C}$ composite

US2014023922A1/ 2014-01-23 [122]
2017-07-07/

Univ. Pittsburgh Sys. Higher Education UChicago Argonne LLC Commonwealth

Polymer electrolyte separator that comprises electrospun nanofibers, a

lithium/magnesium/sodium solid or liquid electrolyte and nanoparticle filler (metal oxides and metal non-oxide, groups III, IV, or V)

A non-aqueous electrolyte comprising a salt, a non-aqueous solvent, and a compound containing $\mathrm{S}(\mathrm{O})$-or $\mathrm{S}(\mathrm{O})_{2}$ - groups for diverse uses including

$\mathrm{Na}-\mathrm{S}$-batteries

2018-07-06/

Hydro Quebec \&

Murata

Manufacturing Co.

2012-03-28 and others/

Sharp Lab. of

America Inc.

2017-09-27/

Korea Institute of

Energy Research

compositions

Glycidyl-containing polymers and polymer compositions for uses in electrode materials and/or as coatings for battery components

A reactive separator for a metal-ion battery made up of a reactive layer that is chemically reactive to alkali or alkaline earth metals, and has a first side and a second side

Methodology for preparation of core-shell nanoparticles of various components and compositions

Novel polystyrene sulfonic

2011-11-16/ $\mathrm{H}$. Matsunaga; $\mathrm{S}$. Ozoe; Tosoh Organic Chemical Co. Ltd. \& K. Yamanoi

acid (salt) useful as a dispersant for producing an aqueous dispersion of a nanocarbon material or an aqueous dispersion of a conductive polymer

Composite polymer

electrolyte separators for lithium batteries and extended to sodium and magnesium batteries

The electrolyte can be used in electrochemical devices that may include diverse types of nanomaterials in some of their components, for instance carbon nanotubes, carbon nanofibers, graphene, tin nanoparticles, and others

The polymer may be used in the preparation of electrode materials to disperse nanoparticles

The reactive layer may be formed as a porous membrane (carbon or a porous polymer) embedded with reactive components or is formed as a polymer gel embedded with reactive components

Possible use of core-shell nanoparticles as components of electrode materials in lithium and sodium batteries

The material can be used as a dispersant for producing carbon nanomaterials, such as carbon nanotubes, graphene, or fullerenes that can be used as electrode protective film and separator for sodium secondary battery material

2020-04-20/

Jixi Weida New

Material Tech Co.

Ltd.; Univ Science

\& Technology

Liaoning

Manufacturing method

of an electrode for an electrochemical element
2011-01-21 \&

others/

Y. Isshiki Yasuhiro;

Y. Wakizaka \&

Zeon Corp.
Method for preparation an iron sulfide/carbon composite material for potential use as electrode in lithium and potentially other alkaline-ion batteries

Method to produce an electrode for an

; electrochemical element having a superior adhesion
Combination of sulfide nanoparticles and the carbon component improve the conductivity of the anode materials and also act as a structural buffer

The electrode material (a mixed powder or composite particles) includes an alkaline metal powder for uses in diverse alkaline batteries 
structured sodium, though from the ambiguous language of these documents it is challenging to ascertain if such issues were addressed. It must be noted that only patents registered by companies were analyzed in this study. It is possible that academic institutions may have already protected methodologies or materials introduced in this review. Besides, it could be expected that the increasing research and technological relevance will translate in an increasing number of patents and actual transfer to the productive sector.

\section{Conclusion}

The revival of $\mathrm{Na}-\mathrm{S}$ batteries has triggered enormous research within this field. Important drivers are, besides the high theoretical capacity and energy density values, aspects of sustainability, environmental impact, and geo-economic concerns. Sodium and sulfur are amongst the most abundant elements on Earth, widely available and with a relatively small ecological footprint. They also do not require the same amount of rare and socially contested metals as LiBs. The substitution of cobaltbased electrocatalytic NPs in RT Na-S with less critical transition metal and noble metal NPs would further improve their environmental performance. It is expected that sodium batteries will replace LiBs at some point in the future and sustain further electrification of the daily life, an important pillar of sustainable development in a post-carbon society. However, important obstacles have to be overcome to make this vision come true, especially in the case of RT Na-S batteries. While they share important electrochemical challenges with $\mathrm{Li}-\mathrm{S}$ and sodium-ion batteries, some aspects are more pronounced or unique to RT $\mathrm{Na}-\mathrm{S}$. The polysulfide shuttle effect is a serious drawback lowering the life cycle stability and Coulombic efficiency. Likewise, the severe dendrite growth in $\mathrm{Na}-\mathrm{S}$ is much more prominent than in Li-S batteries, affecting the safety of the batteries as well as reducing the cycling performance and capacity. More specific issues are the slow reaction kinetics between $\mathrm{Na}$ and $\mathrm{S}$ and the low electrical conductivity of sulfur and $\mathrm{Na}_{2} \mathrm{~S}$. Volume expansion that leads to material breakdown is a threat both at the cathode and the anode side, especially in case of sodiated alloys. It was shown that down-sizing the active components on both electrodes is a viable strategy to mitigate many of these issues. Nanostructured and nanoparticulated sulfur is easily entrapped in electroconducting matrices, which reduces the shuttle effect, increases the cathode conductivity, accommodates mechanical stress from volume expansion. Also, the high surface area accelerates reaction kinetics. A similar strategy can be pursued at the $\mathrm{Na}$ anode, where nanosized $\mathrm{Na}$ alloys can reduce dilative material failure and $\mathrm{Na}$ dendrite growth. Especially the focus on Na metal-free anodes is foreseen as an important element on the way to commercial RT Na-S batteries. Since much progress has been achieved in the understanding of sodium intercalation in anode materials of $\mathrm{SiBs}$, this know- ledge should now be transferred to RT Na-S batteries to increase their safety and applicability.

The patent survey also revealed quite clearly the gap that exists between academic and industrial RT Na-S battery research, where the former flourishes with a diversity of concepts and material designs, while the latter is much more narrow in terms of material development. For instance, sulfur nanoparticles or nanostructured sulfur compounds do not appear in $\mathrm{Na}-\mathrm{S}$ patents, whereas they do in some Li-S patents. It is also striking that there are no commercial RT Na-S batteries as of today, which underscores the long way to go for this technology. While the challenges are still numerous and severe, a breakthrough would allow for more efficient energy storage for meeting the sustainable development goals.

\section{Funding}

Financial support from the Agencia Estatal de Investigación (AEI, Spain) and the FEDER Program (EU) is acknowledged (MAT2015-71117-R and PID2019-105479RB-I00 projects). BW also thanks the MICINN for a JIN contract (PID2019107022RJ-I00).

\section{ORCID ${ }^{\circledR}$ iDs}

Marina Tabuyo-Martínez - https://orcid.org/0000-0002-8210-9565 Bernd Wicklein - https://orcid.org/0000-0002-1811-6736

Pilar Aranda - https://orcid.org/0000-0003-2196-0476

\section{References}

1. Hirsh, H. S.; Li, Y.; Tan, D. H. S.; Zhang, M.; Zhao, E.; Meng, Y. S. Adv. Energy Mater. 2020, 10, 2001274. doi:10.1002/aenm.202001274

2. Gür, T. M. Energy Environ. Sci. 2018, 11, 2696-2767. doi:10.1039/c8ee01419a

3. Kumar, D.; Rajouria, S. K.; Kuhar, S. B.; Kanchan, D. K. Solid State lonics 2017, 312, 8-16. doi:10.1016/j.ssi.2017.10.004

4. Liu, D.; Li, Z.; Li, X.; Cheng, Z.; Yuan, L.; Huang, Y. ChemPhysChem 2019, 20, 3164-3176. doi:10.1002/cphc.201900595

5. Ponrouch, A.; Palacín, M. R. Philos. Trans. R. Soc., A 2019, 377, 20180297. doi:10.1098/rsta.2018.0297

6. Muñoz-Márquez, M. Á.; Saurel, D.; Gómez-Cámer, J. L.; Casas-Cabanas, M.; Castillo-Martínez, E.; Rojo, T. Adv. Energy Mater. 2017, 7, 1700463. doi:10.1002/aenm.201700463

7. Liu, F.; Wang, T.; Liu, X.; Fan, L.-Z. Adv. Energy Mater. 2021, 11, 2000787. doi:10.1002/aenm.202000787

8. Abundance of Elements in the Earth's Crust and in the Sea. In CRC Handbook of Chemistry and Physics; Lide, D. R., Ed.; CRC Press; pp 14-17.

9. Walter, M.; Kovalenko, M. V.; Kravchyk, K. V. New J. Chem. 2020, 44, 1677-1683. doi:10.1039/c9nj05682c

10. Sun, B.; Xiong, P.; Maitra, U.; Langsdorf, D.; Yan, K.; Wang, C.; Janek, J.; Schröder, D.; Wang, G. Adv. Mater. (Weinheim, Ger.) 2020, 32, 1903891. doi:10.1002/adma.201903891

11. Manthiram, A.; Fu, Y.; Su, Y.-S. Acc. Chem. Res. 2013, 46, 1125-1134. doi:10.1021/ar300179v 
12. Tang, W.; Zhong, W.; Wu, Y.; Qi, Y.; Guo, B.; Liu, D.; Bao, S.-J.; Xu, M. Chem. Eng. J. 2020, 395, 124978. doi:10.1016/j.cej.2020.124978

13. Nikiforidis, G.; van de Sanden, M. C. M.; Tsampas, M. N. RSC Adv. 2019, 9, 5649-5673. doi:10.1039/c8ra08658c

14. Wang, Y.-X.; Lai, W.-H.; Chou, S.-L.; Liu, H.-K.; Dou, S.-X. Adv. Mater. (Weinheim, Ger.) 2020, 32, 1903952. doi:10.1002/adma.201903952

15. Zhu, J.; Abdelkader, A.; Demko, D.; Deng, L.; Zhang, P.; He, T.; Wang, Y.; Huang, L. Molecules 2020, 25, 1585. doi:10.3390/molecules25071585

16. Wang, Y.-X.; Zhang, B.; Lai, W.; Xu, Y.; Chou, S.-L.; Liu, H.-K.; Dou, S.-X. Adv. Energy Mater. 2017, 7, 1770140. doi:10.1002/aenm.201770140

17. Yu, X.; Manthiram, A. ChemElectroChem 2014, 1, 1275-1280. doi:10.1002/celc.201402112

18. Kumar, D.; Kuhar, S. B.; Kanchan, D. K. J. Energy Storage 2018, 18, 133-148. doi:10.1016/j.est.2018.04.021

19. Lee, B.; Paek, E.; Mitlin, D.; Lee, S. W. Chem. Rev. 2019, 119, 5416-5460. doi:10.1021/acs.chemrev.8b00642

20. Lee, D.-J.; Park, J.-W.; Hasa, I.; Sun, Y.-K.; Scrosati, B.; Hassoun, J. J. Mater. Chem. A 2013, 1, 5256-5261. doi:10.1039/c3ta10241f

21. Vijaya Kumar Saroja, A. P.; Kamaraj, M.; Sundara, R. J. Phys. Chem. C 2020, 124, 7615-7623. doi:10.1021/acs.jpcc.9b10825

22. Yu, X.; Manthiram, A. J. Phys. Chem. C 2014, 118, 22952-22959. doi:10.1021/jp507655u

23. Zhu, T.; Dong, X.; Liu, Y.; Wang, Y.-G.; Wang, C.; Xia, Y.-Y. ACS Appl. Energy Mater. 2019, 2, 5263-5271. doi:10.1021/acsaem.9b00953

24. Zhang, L.; Zhang, B.; Dou, Y.; Wang, Y.; Al-Mamun, M.; Hu, X.; Liu, H. ACS Appl. Mater. Interfaces 2018, 10, 20422-20428. doi:10.1021/acsami.8b03850

25. Kohl, M.; Borrmann, F.; Althues, H.; Kaskel, S. Adv. Energy Mater. 2016, 6, 1502185. doi:10.1002/aenm.201502185

26. Kalisvaart, W. P.; Olsen, B. C.; Luber, E. J.; Buriak, J. M. ACS Appl. Energy Mater. 2019, 2, 2205-2213. doi:10.1021/acsaem.8b02231

27. Bloi, L. M.; Pampel, J.; Dörfler, S.; Althues, H.; Kaskel, S. Adv. Energy Mater. 2020, 10, 1903245. doi:10.1002/aenm.201903245

28. Syali, M. S.; Kumar, D.; Mishra, K.; Kanchan, D. K. Energy Storage Mater. 2020, 31, 352-372. doi:10.1016/j.ensm.2020.06.023

29. Carter, R.; Oakes, L.; Douglas, A.; Muralidharan, N.; Cohn, A. P.; Pint, C. L. Nano Lett. 2017, 17, 1863-1869. doi:10.1021/acs.nanolett.6b05172

30. Hu, L.; Lu, Y.; Zhang, T.; Huang, T.; Zhu, Y.; Qian, Y. ACS Appl. Mater. Interfaces 2017, 9, 13813-13818. doi:10.1021/acsami.7b01387

31. Qiang, Z.; Chen, Y.-M.; Xia, Y.; Liang, W.; Zhu, Y.; Vogt, B. D. Nano Energy 2017, 32, 59-66. doi:10.1016/j.nanoen.2016.12.018

32. Xia, G.; Zhang, L.; Chen, X.; Huang, Y.; Sun, D.; Fang, F.; Guo, Z.; Yu, X. Energy Storage Mater. 2018, 14, 314-323. doi:10.1016/j.ensm.2018.05.008

33. Chen, Y.-M.; Liang, W.; Li, S.; Zou, F.; Bhaway, S. M.; Qiang, Z.; Gao, M.; Vogt, B. D.; Zhu, Y. J. Mater. Chem. A 2016, 4, 12471-12478. doi:10.1039/c6ta04529d

34. Ma, Q.; Du, G.; Guo, B.; Tang, W.; Li, Y.; Xu, M.; Li, C. Chem. Eng. J. 2020, 388, 124210. doi:10.1016/j.cej.2020.124210
35. Huo, X.; Liu, Y.; Li, R.; Li, J. lonics 2019, 25, 5373-5382. doi:10.1007/s11581-019-03074-6

36. Yan, J.; Li, W.; Wang, R.; Feng, P.; Jiang, M.; Han, J.; Cao, S.; Zhang, Z.; Wang, K.; Jiang, K. ACS Energy Lett. 2020, 5, 1307-1315. doi:10.1021/acsenergylett.0c00492

37. Wu, T.; Jing, M.; Yang, L.; Zou, G.; Hou, H.; Zhang, Y.; Zhang, Y.; Cao, X.; Ji, X. Adv. Energy Mater. 2019, 9, 1803478. doi:10.1002/aenm.201803478

38. Wang, L.; Chen, X.; Li, S.; Yang, J.; Sun, Y.; Peng, L.; Shan, B.; Xie, J. J. Mater. Chem. A 2019, 7, 12732-12739. doi:10.1039/c9ta02831e

39. Hwang, T. H.; Jung, D. S.; Kim, J.-S.; Kim, B. G.; Choi, J. W. Nano Lett. 2013, 13, 4532-4538. doi:10.1021/nl402513x

40. Kim, I.; Kim, C. H.; Choi, S. h.; Ahn, J.-P.; Ahn, J.-H.; Kim, K.-W.; Cairns, E. J.; Ahn, H.-J. J. Power Sources 2016, 307, 31-37. doi:10.1016/j.jpowsour.2015.12.035

41. Li, Z.; Zhang, J.; Lu, Y.; Lou, X. W. Sci. Adv. 2018, 4, eaat1687. doi:10.1126/sciadv.aat1687

42. Yu, X.; Manthiram, A. J. Phys. Chem. Lett. 2014, 5, 1943-1947. doi:10.1021/jz500848x

43. Ceylan Cengiz, E.; Erdol, Z.; Sakar, B.; Aslan, A.; Ata, A.; Ozturk, O.; Demir-Cakan, R. J. Phys. Chem. C 2017, 121, 15120-15126. doi:10.1021/acs.jpcc.7b04711

44. Zheng, S.; Han, P.; Han, Z.; Li, P.; Zhang, H.; Yang, J. Adv. Energy Mater. 2014, 4, 1400226. doi:10.1002/aenm.201400226

45. Zhang, B.-W.; Sheng, T.; Liu, Y.-D.; Wang, Y.-X.; Zhang, L.; Lai, W.-H.; Wang, L.; Yang, J.; Gu, Q.-F.; Chou, S.-L.; Liu, H.-K.; Dou, S.-X. Nat. Commun. 2018, 9, 4082. doi:10.1038/s41467-018-06144-X

46. Du, W.; Gao, W.; Yang, T.; Guo, B.; Zhang, L.; Bao, S.-j.; Chen, Y.; Xu, M. J. Colloid Interface Sci. 2020, 565, 63-69. doi:10.1016/j.jcis.2020.01.010

47. Zhang, B.-W.; Sheng, T.; Wang, Y.-X.; Chou, S.; Davey, K.; Dou, S.-X.; Qiao, S.-Z. Angew. Chem. 2018, 131, 1498-1502. doi:10.1002/ange.201811080

48. Yan, Z.; Liang, Y.; Xiao, J.; Lai, W.; Wang, W.; Xia, Q.; Wang, Y.; Gu, Q.; Lu, H.; Chou, S.-L.; Liu, Y.; Liu, H.; Dou, S.-X. Adv. Mater. (Weinheim, Ger.) 2020, 32, 1906700. doi:10.1002/adma.201906700

49. Wang, N.; Wang, Y.; Bai, Z.; Fang, Z.; Zhang, X.; Xu, Z.; Ding, Y.; Xu, X.; Du, Y.; Dou, S.; Yu, G. Energy Environ. Sci. 2020, 13, 562-570. doi:10.1039/c9ee03251g

50. Yan, Z.; Xiao, J.; Lai, W.; Wang, L.; Gebert, F.; Wang, Y.; Gu, Q.; Liu, H.; Chou, S.-L.; Liu, H.; Dou, S.-X. Nat. Commun. 2019, 10, 4793. doi:10.1038/s41467-019-11600-3

51. Kumar, A.; Ghosh, A.; Roy, A.; Panda, M. R.; Forsyth, M.; MacFarlane, D. R.; Mitra, S. Energy Storage Mater. 2019, 20 , 196-202. doi:10.1016/j.ensm.2018.11.031

52. Eng, A. Y. S.; Kumar, V.; Zhang, Y.; Luo, J.; Wang, W.; Sun, Y.; Li, W.; Seh, Z. W. Adv. Energy Mater. 2021, 11, 2003493. doi:10.1002/aenm.202003493

53. Xu, Z.; Fu, H.; Yao, K.; Shen, X.; Li, Z.; Fu, L.; Huang, J.; Li, J. Batteries Supercaps 2018, 1, 184-191. doi:10.1002/batt.201800060

54. Vijaya Kumar Saroja, A. P.; Kamaraj, M.; Ramaprabhu, S. J. Alloys Compd. 2020, 818, 152864. doi:10.1016/j.jallcom.2019.152864

55. Zhang, S.; Xiao, W.; Zhang, Y.; Liu, K.; Zhang, X.; Zhao, J.; Wang, Z.; Zhang, P.; Shao, G. J. Mater. Chem. A 2018, 6, 22555-22565. doi:10.1039/c8ta06869k 
56. Lu, Q.; Wang, X.; Cao, J.; Chen, C.; Chen, K.; Zhao, Z.; Niu, Z.; Chen, J. Energy Storage Mater. 2017, 8, 77-84. doi:10.1016/j.ensm.2017.05.001

57. Steudel, R. Aqueous Sulfur Sols. In Elemental Sulfur and Sulfur-Rich Compounds I; Steudel, R., Ed.; Topics in Current Chemistry, Vol. 230; Springer: Berlin, Heidelberg, 2012; pp 153-166. doi:10.1007/b12113

58. Chen, K.; Cao, J.; Lu, Q.; Wang, Q.; Yao, M.; Han, M.; Niu, Z.; Chen, J. Nano Res. 2018, 11, 1345-1357. doi:10.1007/s12274-017-1749-2

59. Moo, J. G. S.; Omar, A.; Jaumann, T.; Oswald, S.; Balach, J.; Maletti, S.; Giebeler, L. C-Open Access Carbon Res. J. 2018, 4, 2. doi:10.3390/c4010002

60. Qu, L.; Liu, P.; Tian, X.; Shu, C.; Yi, Y.; Yang, P.; Wang, T.; Fang, B.; Li, M.; Yang, B. ChemElectroChem 2020, 7, 1679-1688. doi:10.1002/celc.202000163

61. Wadekar, P. H.; Ghosh, A.; Khose, R. V.; Pethsangave, D. A.; Mitra, S.; Some, S. Electrochim. Acta 2020, 344, 136147. doi:10.1016/j.electacta.2020.136147

62. Tan, Z.; Shi, Y.; Wei, T.; Jia, X.; Lv, Y.; Chen, L.; Guo, X. New J. Chem. 2020, 44, 466-471. doi:10.1039/c9nj05035c

63. Hong, X.; Mei, J.; Wen, L.; Tong, Y.; Vasileff, A. J.; Wang, L.; Liang, J.; Sun, Z.; Dou, S. X. Adv. Mater. (Weinheim, Ger.) 2019, 31 , 1802822. doi:10.1002/adma.201802822

64. Zheng, J.; Chen, S.; Zhao, W.; Song, J.; Engelhard, M. H.; Zhang, J.-G. ACS Energy Lett. 2018, 3, 315-321. doi:10.1021/acsenergylett.7b01213

65. Yang, X.; Rogach, A. L. Adv. Energy Mater. 2020, 10, 2000288. doi:10.1002/aenm.202000288

66. Liu, T.; Yang, X.; Nai, J.; Wang, Y.; Liu, Y.; Liu, C.; Tao, X. Chem. Eng. J. 2021, 409, 127943. doi:10.1016/j.cej.2020.127943

67. Luo, W.; Zhang, Y.; Xu, S.; Dai, J.; Hitz, E.; Li, Y.; Yang, C.; Chen, C.; Liu, B.; Hu, L. Nano Lett. 2017, 17, 3792-3797. doi:10.1021/acs.nanolett.7b01138

68. Chi, S.-S.; Qi, X.-G.; Hu, Y.-S.; Fan, L.-Z. Adv. Energy Mater. 2018, 8, 1702764. doi:10.1002/aenm.201702764

69. Zhang, Q.; Lu, Y.; Zhou, M.; Liang, J.; Tao, Z.; Chen, J. Inorg. Chem. Front. 2018, 5, 864-869. doi:10.1039/c7qi00802c

70. Wang, S.; Liu, Y.; Lu, K.; Cai, W.; Jie, Y.; Huang, F.; Li, X.; Cao, R.; Jiao, S. Energy Fuels 2021, 35, 4587-4595. doi:10.1021/acs.energyfuels.0c04408

71. Xu, Y.; Menon, A. S.; Harks, P. P. R. M. L.; Hermes, D. C.; Haverkate, L. A.; Unnikrishnan, S.; Mulder, F. M. Energy Storage Mater. 2018, 12, 69-78. doi:10.1016/j.ensm.2017.11.011

72. Liu, S.; Tang, S.; Zhang, X.; Wang, A.; Yang, Q.-H.; Luo, J. Nano Lett. 2017, 17, 5862-5868. doi:10.1021/acs.nanolett.7b03185

73. Edison, E.; Sreejith, S.; Lim, C. T.; Madhavi, S. Sustainable Energy Fuels 2018, 2, 2567-2582. doi:10.1039/c8se00381e

74. Wang, J. W.; Liu, X. H.; Mao, S. X.; Huang, J. Y. Nano Lett. 2012, 12 , 5897-5902. doi:10.1021/nl303305c

75. He, J.; Wei, Y.; Zhai, T.; Li, H. Mater. Chem. Front. 2018, 2, 437-455. doi:10.1039/c7qm00480j

76. Chang, G.; Zhao, Y.; Dong, L.; Wilkinson, D. P.; Zhang, L.; Shao, Q.; Yan, W.; Sun, X.; Zhang, J. J. Mater. Chem. A 2020, 8, 4996-5048. doi:10.1039/c9ta12169b

77. Wang, H.; Matios, E.; Wang, C.; Luo, J.; Lu, X.; Hu, X.; Zhang, Y.; Li, W. J. Mater. Chem. A 2019, 7, 23747-23755. doi:10.1039/c9ta05176g
78. Wu, L.; Hu, X.; Qian, J.; Pei, F.; Wu, F.; Mao, R.; Ai, X.; Yang, H.; Cao, Y. Energy Environ. Sci. 2014, 7, 323-328. doi:10.1039/c3ee42944j

79. Zhang, N.; Liu, Y.; Lu, Y.; Han, X.; Cheng, F.; Chen, J. Nano Res. 2015, 8, 3384-3393. doi:10.1007/s12274-015-0838-3

80. Wan, F.; Guo, J.-Z.; Zhang, X.-H.; Zhang, J.-P.; Sun, H.-Z.; Yan, Q.; Han, D.-X.; Niu, L.; Wu, X.-L. ACS Appl. Mater. Interfaces 2016, 8, 7790-7799. doi:10.1021/acsami.5b12242

81. Gao, H.; Zhou, T.; Zheng, Y.; Liu, Y.; Chen, J.; Liu, H.; Guo, Z. Adv. Energy Mater. 2016, 6, 1601037. doi:10.1002/aenm.201601037

82. Li, Z.; Chen, Y.; Jian, Z.; Jiang, H.; Razink, J. J.; Stickle, W. F.; Neuefeind, J. C.; Ji, X. Chem. Mater. 2018, 30, 4536-4542. doi:10.1021/acs.chemmater.8b00645

83. Mao, J.; Zhou, T.; Zheng, Y.; Gao, H.; Liu, H. k.; Guo, Z. J. Mater. Chem. A 2018, 6, 3284-3303. doi:10.1039/c7ta10500b

84. Xu, S.; Fan, X.; Liu, J.; Jiang, Q.; Zheng, W.; Singh, D. J. Electrochim. Acta 2019, 297, 497-503. doi:10.1016/j.electacta.2018.12.008

85. Alvin, S.; Yoon, D.; Chandra, C.; Cahyadi, H. S.; Park, J.-H.; Chang, W.; Chung, K. Y.; Kim, J. Carbon 2019, 145, 67-81. doi:10.1016/j.carbon.2018.12.112

86. Liu, M.; Zhang, J.; Guo, S.; Wang, B.; Shen, Y.; Ai, X.; Yang, H.; Qian, J. ACS Appl. Mater. Interfaces 2020, 12, 17620-17627. doi:10.1021/acsami.0c02230

87. European Patent Office. ESPACENET Patent Search. https://worldwide.espacenet.com/patent/ (accessed Jan 13, 2021).

88. Jang, B. Z.; Zhamu, A. Alkali Metal-Sulfur Batteries Having High Volumetric and Gravimetric Energy Densities. W.O. Pat. 2017048341A1, March 23, 2017.

89. Alasaarela, T.; Brown, D.; Gómez-Torregrosa, R.; Kovacs, A.; Orts-Mateo, J. M.; Ruiz-Martinez, D. Electrochemical Secondary Cells for High-Energy or High-Power Battery Use. W.O. Pat. 2017055678A1, April 6, 2017.

90. Jang, B. Z.; Zhamu, A. Alkali Metal-Sulfur Batteries Having High Volumetric and Gravimetric Energy Densities. W.O. Pat. 2017123544 A1, July 20, 2017.

91. Jang, B. Z.; Zhamu, A. Method of Producing Alkali Metal or Alkali-lon Batteries Having High Volumetric and Gravimetric Energy Densities. W.O. Pat. 2017123546A1, July 20, 2017.

92. Alasaarela, T.; Brown, D.; Gómez-Torregrosa, R.; Kovacs, A.; Ruiz-Martinez, D. Rechargeable Sodium Cells for High Energy Density Battery Use. W.O. Pat. 2017149204A2, Sept 8, 2017.

93. He, H.; Jang, B. Z.; Pan, B.; Su, Y. S.; Zhamu, A. Flexible and Shape-Conformal Cable-Type Alkali Metal Batteries. W.O. Pat. 2018118800A1, June 28, 2018.

94. Jang, B. Z.; Liu, C.; Zhamu, A. Rolled Alkali Metal Batteries and Production Process. W.O. Pat. 2018208660A1, Nov 15, 2018.

95. Jang, B. Z.; Zhamu, A. Alkali Metal Battery Having a Deformable Quasi-Solid Electrode Material. W.O. Pat. 2018217274A1, Nov 29, 2018.

96. Jang, B. Z.; Zhamu, A. Shape-Conformable Alkali Metal Battery Having a Conductive and Deformable Quasi-Solid Polymer Electrode. W.O. Pat. 2018222348A1, Dec 6, 2018.

97. Jang, B. Z.; Zhamu, A. Shape-Conformable Alkali Metal-Sulfur Battery. W.O. Pat. 2018222349A1, Dec 6, 2018.

98. Jang, B. Z.; Zhamu, A. Shape-Conformable Alkali Metal-Sulfur Battery Having a Deformable and Conductive Quasi-Solid Electrode. W.O. Pat. 2019005299A1, Jan 3, 2019.

99. Jang, B. Z.; Zhamu, A. Continuous Process for Producing Electrochemical Cells. W.O. Pat. 2019045907A1, March 7, 2019. 
100. Ishikawa, T.; Komaba, S.; Kuze, S.; Matsuura, Y.; Murata, W.; Yabuuchi, N. Sodium Secondary Cell Electrode and Sodium Secondary Cell. W.O. Pat. 2012128262A1, Sept 27, 2012.

101. Abouimrane, A.; Amine, K.; Ren, J.; Yang, J. Composite Materials for Battery Applications. W.O. Pat. 2012151094A2, Nov 8, 2012.

102. Bodnarchuk, M.; Kovalenko, M. V.; Kravchyk, K. Tin Based Anode Material for a Rechargeable Battery and Preparation Method. W.O. Pat. 2014083135A1, June 5, 2014.

103. Naskar, A. K.; Paranthaman, M. P. Pyrolytic Carbon Black Composite and Method of Making the Same. U.S. Pat. 10320000B2, June 11, 2019.

104.Kovalenko, M. V.; Kravchyk, K.; Meng, H.; Walter, M. Antimony Based Anode Material for Rechargeable Batteries and Preparation Method. U.S. Pat. 2017155140A1, June 1, 2017.

105.Jang, B. Z.; Zhamu, A. Continuous Process for Producing Electrodes and Alkali Metal Batteries Having Ultra-High Energy Densities. W.O. Pat. 2017062197A1, April 13, 2017.

106. Korzhenko, A.; Mercader, C. New Process for Producing Highly Carbonaceous Materials and the Highly Carbonaceous Material Obtained. U.S. Pat. 2019270678A1, Sept 5, 2019.

107.He, H.; Jang, B. Z.; Pan, B.; Zhamu, A. Anode Particulates or Cathode Particulates and Alkali Metal Batteries Containing Same. W.O. Pat. 2019108343A1, June 6, 2019.

108. He, H.; Jang, B. Z.; Pan, B.; Zhamu, A. Anode Particulates or Cathode Particulates and Alkali Metal Batteries Containing Same. U.S. Pat. 10637043B2, April 28, 2020.

109.He, H.; Jang, B. Z.; Pan, B.; Zhamu, A. Anode Particulates or Cathode Particulates and Alkali Metal Batteries. U.S. Pat. 10873083B2, Dec 22, 2020.

110.He, H.; Jang, B. Z.; Pan, B.; Zhamu, A. Method of Producing Participate Electrode Materials for Alkali Metal Batteries. U.S. Pat. 2019173079A1, June 6, 2019.

111. He, H.; Jang, B. Z.; Pan, B.; Zhamu, A. Method of Producing Anode or Cathode Particulates for Alkali Metal Batteries. U.S. Pat. 10797313B2, Oct 6, 2020

112.He, H.; Jang, B. Z.; Pan, B.; Zhamu, A. Anode Particulates or Cathode Particulates for Alkali Metal Batteries. W.O. Pat. 2019135827A1, July 11, 2019.

113.Cui, M.; Han, D.; Huang, S.; Liu, X.; Tan, J.; Wu, C. Selenium-Doped Ferrous Disulfide Carbon-Coated Composite Material and Preparation and Application Methods Thereof. C.N. Pat. 109437123A, March 8, 2019.

114.Armand, M.; Ben, Y. H.; Orayech, B.; Rojo, T.; Saurel, D.; Shanmukaraj, D. Solid Polymer Electrolyte Based on Modified Cellulose and Its Use in Lithium or Sodium Secondary Batteries. E.P. Pat. 3422438A1, Jan 2, 2019.

115.Datta, M. K.; Gattu, B.; Hanumantha, P. J.; Kumta, P. N.; Shanthi, P. M.; Velikokhatnyi, O. Electrospinning of PVDF-HFP: Novel Composite Polymer Electrolytes (CPES) with Enhanced Ionic Conductivities for Lithium-Sulfur Batteries. W.O. Pat. 2019010474A1, Jan 10, 2019.

116. Amine, K.; He, M.; Su, C. C. Non-Aqueous Electrolytes for Electrochemical Cells. U.S. Pat. 2020251781A1, Aug 6, 2020.

117. Asakawa, Y.; Daigle, J.-C.; Zaghib, K. Glycidyl-Containing Polymers, Polymer Compositions Comprising Them and Their Use in Electrochemical Cells. W.O. Pat. 2020006642A1, Jan 9, 2020.

118. Lu, Y.; Wang, L. Reactive Separator for a Metal-Ion Battery. U.S. Pat. 2014205883A1, July 24, 2014.
119.Choi, J. Y.; Han, J. H.; Hwang, G. S.; Jang, M. S.; Jeong, N. J.; Jwa, E. J.; Kim, C. S.; Kim, H. G.; Nam, J. Y.; Park, S. C.; Seo, Y. S.; Yang, S. C. The Preparation Method of Multi-Layer Core-Shell Nano Particles Comprising Porous Carbon Shell and Core-Shell Nano Particles Thereby. K.R. Pat. 102001454B1, July 18, 2019.

120. Matsunaga, H.; Ozoe, S.; Yamanoi, K. High-Purity Parastyrene Sulfonic Acid (Salt); Polystyrene Sulfonic Acid (Salt) Using Same; Dispersant, Conductive Polymer Dopant, Aqueous Nanocarbon Material Dispersion and Aqueous Conductive Polymer Dispersion Each Using Polystyrene Sulfonic Acid (Salt). W.O. Pat. 2013073259A1, May 23, 2013.

121.Gao, M.; Li, J.; Wang, Y.; Xu, G.; Zhou, W. Preparation Method of $\mathrm{Fe}_{7} \mathrm{~S}_{8} / \mathrm{C}$ Composite Material. C.N. Pat. 111517374A, Aug 11, 2020.

122. Isshiki, Y.; Wakizaka, Y. Manufacturing Method of an Electrode for Electrochemical Element and an Electrochemical Element. U.S. Pat. 2014023922A1, Jan 23, 2014.

\section{License and Terms}

This is an Open Access article under the terms of the Creative Commons Attribution License (https://creativecommons.org/licenses/by/4.0). Please note that the reuse, redistribution and reproduction in particular requires that the author(s) and source are credited and that individual graphics may be subject to special legal provisions.

The license is subject to the Beilstein Journal of Nanotechnology terms and conditions: (https://www.beilstein-journals.org/bjnano/terms)

The definitive version of this article is the electronic one which can be found at: https://doi.org/10.3762/bjnano.12.75 